\title{
LA ARMONÍA EN EL TECLADO O EL PARTIMENTO COMO ESTRATEGIA METODOLÓGICA PARA LA ENSENANANZA DE LA IMPROVISACIÓN Y EL APRENDIZAJE DEL LENGUAJE MUSICAL
}

\section{KEYBOARD HARMONY OR PARTIMENTO AS A METHODOLOGICAL STRATEGY FOR TEACHING IMPROVISATION AND LEARNING MUSICAL LANGUAGE}

Andrés Benavides Isaza ${ }^{1}$

abil58@hotmail.com

DOI: $10.17230 /$ ricercare.2016.6.1

1 Extracto de la tesis de Maestría de la Haute École de Musique de Genève", Ginebra, Suiza 


\section{Resumen}

La intención detrás de este artículo es presentar y proveer una alternativa metodológica para enseñar la improvisación musical en un contexto académico en el que se transmite o se enseña la música llamada clásica o académica. Este acercamiento cubre las bases de realización del partimento y del bajo continuo, pasa por el Romanticismo y llega hasta los rudimentos o fundamentos del lenguaje del jazz, que es una herramienta muy efectiva para construir un puente conector entre tradiciones musicales (la música académica de origen europeo y el jazz) y comprender el impresionismo francés de finales del siglo XIX. Detrás de esta aproximación a la enseñanza de la armonía en el teclado está el interés en instaurar la improvisación como un elemento esencial para la formación del músico académico y, si no ha de ser una meta alcanzable en el corto plazo, enunciar los beneficios que implica una apropiación acelerada del lenguaje musical.

Palabras clave: partimento, improvisación, armonía en el teclado, bajo continuo.
Abstract

The intention behind this article is to present and provide a methodological alternative for teaching musical improvisation within an academic context in which Art Music is transmitted. This pedagogical approach covers the basics of partimento and thorough bass realization, passing through Romanticism until getting to the rudiments and fundamentals of jazz language, these latest serving as an effective tool for building a connecting bridge between musical traditions (european Art Music and Jazz) for the comprehension of French Impressionism of the late 19th century. Behind all this pedagogical approach to keyboard-harmony teaching is the interest in installing the practice of improvisation as an essential element for the classical musician's formation and, should it be not an achievable goal in the short term, stating the benefits which imply an accelerated appropriation of musical language.

Keywords: partimento, improvisation, keyboard harmony, thorough bass. 


\section{Introducción}

Cuando hoy se escucha una obra de Bach o de Mozart, la mayoría de la gente no se imagina que dicha música podría ser improvisada. La realidad es todo lo contrario. Todas las músicas del pasado están enraizadas en la improvisación. Incluso los géneros más complejos, como las fugas de Bach o las polifonías del Renacimiento. Cuando los músicos escribían una composición, era para poderla perfeccionar en todos sus detalles, para que sus alumnos las tocaran o para enseñarles.

En las tradiciones musicales en las que oralidad aún es esencial para su preservación, como las músicas populares o el jazz, la música se aborda como una lengua: se aprende su vocabulario, su gramática, su dicción, su retórica, etc. La meta siempre será obtener un dominio completo del lenguaje musical por medio del que uno mismo sea capaz de crear la música, es decir, componer e improvisar, como en una lengua viva que se aprende a hablar antes de leer. "Improvisar es a la música lo que hablar es al lenguaje verbal" (Festival de Musique Improvisée de Lausanne, s.f.). En contraste, los músicos académicos o "clásicos" actuales se forman de manera exclusiva para ser capaces de ejecutar la música escrita. Es una tradición en la que la música no existe sin la presencia de una partitura, donde hacer música es en esencia un acto de lectura.

No sorprende, entonces, que por ejemplo el término partimento resulte poco familiar para una gran mayoría de músicos que, en la actualidad, perpetúan la tradición musical del occidente europeo, a pesar de la enorme influencia que la tradición musical italiana jugó en el establecimiento del canon de la denominada música "clásica", académica o de arte.

Un partimento es un bosquejo, escrito sobre un solo pentagrama, cuyo propósito principal es servir como guía para la improvisación y la composición al teclado (Sanguinetti, 2012). Sin embargo, su papel se problematiza poco en la historia del desarrollo de las herramientas interpretativas y composicionales de esta tradición.
Estudiar la clase de entrenamiento que recibían los músicos napolitanos e italianos de los siglos XVII y XVIII nos acerca la influencia de dicha práctica, además de replantear los enfoques con los que se aproxima a la interpretación y a la composición musical, lo que posibilita al intérprete actual deconstruir la tradición de su formación, que reposa, de modo obediente, sobre una lectura "textual" de la partitura escrita.

En el transcurso de los siglos XVII y XVIII se sobreentendía que el eje de formación profesional de un músico era la composición. Los papeles de compositor y de ejecutante intérprete no estaban aún separados y la noción de composición estaba ligada en forma íntima con la de improvisación, diferente de la manera como hoy el compositor confía su oficio netamente a la escritura. El papel del músico estaba, por esencia, ligado con la creación y era inconcebible que el arte musical se limitara únicamente a tocar de manera servil los signos plasmados en una partitura.

En el mencionado panorama se creó un sistema muy eficaz para la enseñanza de la composición: el partimento, sofisticación del bajo continuo, que era una guía para la improvisación y servía también como borrador inicial de una posible composición. Este nombre comenzó a aparecer en el transcurso del siglo XVII, pero ya su práctica estaba muy difundida en la música europea a finales del siglo $\mathrm{XV}$ y en el siglo XVI. La tradición pedagógica del partimento y el bajo continuo tomó fuerza considerable en Italia, en particular en Nápoles, en sus cuatro conservatorios, y se esparció por toda Europa. Maestros como Leonardo Leo, Francesco Durante, el padre Mattei y Giovanni Paisiello, entre otros personajes, regirían estas instituciones y se encargarían de preservar la tradición pedagógica y composicional casi durante dos siglos, lo que cimentó las bases de la denominada "música clásica" en Europa.

Hoy quedan, en la mencionada tradición pedagógica, cientos de colecciones de manuscritos de partimenti de los que se sabe muy poco sobre cómo descifrar sus códigos ocultos. La tradición reposaba, en gran parte, en la oralidad, de manera muy similar a las músicas folklóricas, hasta cierto grado también el jazz, y las músicas eruditas de culturas extraoccidentales. 
Gran parte de sus resultados teóricos y pedagógicos se perdió con sus antiguos practicantes y la manera en que su tradición se reinventa hoy en día está basada en hipótesis, puesto que jamás tendremos la posibilidad de escuchar a un Leo o a un Durante improvisar al órgano o al clavecín.

El espíritu industrial y científico del siglo XIX, junto con las guerras y la Revolución Francesa, transformaron de manera sustancial la forma en que se comprendería y se practicaría la tradición, lo que la convirtió, en esencia, en una práctica dividida en dos oficios: el del compositor, ser privilegiado dotado de una sensibilidad única, que se limita casi de manera exclusiva a escribir; y el del ejecutante, artesano que se dedica, en lo fundamental, a leer, memorizar y repetir.

Gracias al surgimiento del jazz, la dinámica de intercambio surgida entre la tradición europea con el nuevo movimiento musical, sumada al fenómeno de investigaciones musicológicas que darían la oportunidad de aparecer al movimiento de interpretación y teoría historicista, renació del olvido la práctica de la improvisación. En Europa ya son varios los centros de enseñanza de música antigua que se dedican de lleno a cultivar la resucitación de la práctica de la improvisación. De ello es pionero el programa de Maestría en Improvisación Historicista en la Schola Cantorum de Basilea, Suiza, liderado por el organista y clavecinista Rudolph Lutz, que ha inspirado la creación de programas similares en Lyon, Francia, y de festivales dedicados al redescubrimiento de esta práctica a partir de la tradición europea, como en Lausana, también en Suiza, y en Leipzig, Alemania.

Este artículo tiene como finalidad exponer una propuesta metodológica para la enseñanza de la improvisación, en un contexto académico, a partir de los rudimentos básicos de elaboración del partimento y el bajo continuo, pasando por el Romanticismo, hasta llegar al jazz, que sirve de puente conector para la comprensión del impresionismo francés. Detrás de esto existe un interés por instaurar esta práctica como elemento esencial de la formación del músico académico para que, de no ser posible lograr dicho ideal en el corto plazo, por lo menos se señalen los beneficios de una disciplina que cataliza la apropiación del lenguaje musical.

\section{Problemática}

La ejecución interpretativa y el lenguaje musical (por lo común conocido como teoría de la música) parecen estar separados en la enseñanza de la música académica actual. Para los estudiantes instrumentistas, el estudio de la teoría musical resulta tedioso y angustioso (Di Marco, 2014) y su aprendizaje es siempre pasivo. El estudiante no se siente involucrado ni motivado por acercarse a ella.

Este panorama amerita aclarar que no hay materias en su totalidad teóricas ni asignaturas completamente prácticas. Por ejemplo, la ejecución y la interpretación también tienen una teoría y el solfeo, por lo general clasificado dentro de lo que mal se denomina "teoría musical", es una materia que prepara al músico a la práctica. De la misma manera, la escritura musical (contrapunto y armonía) es una disciplina que requiere práctica para desarrollarse. Se puede decir, entonces, que aquellas asignaturas que catalogamos como de "teoría" son aquellas que incluyen más contenido teórico que las materias prácticas o que están destinadas a preparar al músico en la abstracción para comprender la práctica musical, como lo son el solfeo, la armonía, el contrapunto, el análisis, la estética, la retórica, la historia, etc.

Dicho lo anterior, se puede plantear que el único paradigma pedagógico en realidad eficaz para eliminar por completo la brecha entre las materias llamadas "teóricas" y las "prácticas" es uno que fomente la improvisación como parte esencial de la práctica musical, pues parece ser que sólo a través de la composición y la improvisación, lo que se conoce como "teoría musical", se vuelve una herramienta indispensable de supervivencia al momento de la ejecución instrumental. Es preciso que se aborde una disciplina que fomente el aprendizaje activo del lenguaje musical. El adiestramiento de la improvisación a través de la armonía práctica se revela como una opción interesante para tal causa.

La música debe aprenderse como una lengua hablada, y en su caso, la improvisación es a ella lo que la oralidad es al lenguaje. La tradición académica, desde hace algo más de doscientos años, ha favorecido un aprendizaje de la música que se asemeja mucho al de las lenguas muertas, como el latín, en el que se aprenden las 
reglas de gramática, el vocabulario, las declinaciones, etc., pero no se enseña a hablar de modo espontáneo. La lógica natural del aprendizaje es que se aprenda primero a hablar antes que a leer y escribir.

No se debe mostrar la tablatura a los niños sino hasta después de que hayan tenido una cierta cantidad de piezas en sus manos. Es casi imposible que, mirando su libro, los dedos no se perturben ni se contorsionen... además, la retentiva se forma mucho mejor al aprender de memoria ${ }^{2}$ (Couperin, 1716, p....).

Esta frase de Couperin sirve para defender que la música debería aprenderse tal como se hace para hablar. Aprender un cierto número de piezas antes de leer la música ayuda al alumno a incorporar un vocabulario a su memoria. Tocar de memoria antes de introducir la lectura musical nos lleva a encontrar una conexión natural con el instrumento para después facilitar la buena comprensión de la escritura sin entorpecer la técnica. Es exactamente el principio de aprendizaje de una lengua y era una idea común en el campo de la enseñanza de la música durante los siglos XVII y XVIII, como lo demuestra el texto de Couperin.

Para aprender a hablar se necesita imitar, algo muy ligado con la improvisación. Esta afirmación está apoyada por el trabajo de investigación de Emmanuel Bigand y Charles Delbé (2010), en el que ponen en paralelo dos ideas al momento de desarrollar el concepto de aprendizaje de una gramática artificial: el aprendizaje implícito y el explícito. La capacidad de imitación para el aprendizaje de una lengua materna se clasifica en la primera categoría y se toma como implícito porque el sujeto aprende sin tener consciencia y ni siquiera la intención, es decir, lo hace sin ser consciente, sin poder explicar la naturaleza de sus conocimientos. Los autores consideran a esta forma de aprendizaje como un proceso cognitivo fundamental que permite adquirir informaciones sobre el ambiente que son muy complejas para acceder a ellas por la vía del razonamiento hipotéticodeductivo. Los procesos de aprendizaje implítos presentan un valor adaptativo fundamental pues entran en escena cuando las informaciones son

2 Cita original en francés: «On devrait ne commencer à montrer la tablature aux enfants qu'après qu'ils ont une certaine quantité de pièces dans les mains. Il est presqu'impossible qu'en regardant leur livre, les doigts ne se dérangent et ne se contorsionnent : que les agréments même n'en soient altérés; d'ailleurs, la mémoire se forme beaucoup mieux en apprenant par cœur». demasiado complejas para ser accesibles a través del pensamiento consciente. La asimilación de las lenguas extranjeras es un ejemplo esquemático que permite contrastar las dos formas de aprendizaje.

Por su parte, el aprendizaje explícito consiste en la adquisición voluntaria y consciente de todo un conjunto de informaciones (semánticas y sintácticas) sobre el sistema lingüístico, que se representan según un formato simbólico que se presta a una utilización voluntaria de parte del sujeto. En ciertos casos, y sobre todo cuando se debe sobrevivir en un país extranjero, optamos con rapidez por implementar otras estrategias, calificadas en ocasiones como aprendizaje por impregnación, basadas en la interiorización tácita de un conjunto de elementos lingüísticos que, sin que tengamos en realidad consciencia, van a permitirnos con celeridad comprender y expresarnos en la lengua en cuestión. La adquisición de una lengua materna se cimenta, en lo primordial, en este tipo de aprendizaje implícito: desde los primeros meses, el recién nacido aprende las estructuras de su lengua de acuerdo con este proceso, sin tener, obviamente, la menor consciencia de qué es una palabra, un artículo, un verbo o un complemento de objeto.

Si bien la tradición oral de la enseñanza de los métodos del partimento se fue a la tumba con los maestros napolitanos, fenómeno quelollevó asíal olvido, a través del aprendizaje de la improvisación se busca revivir su idea pedagógica para que haya un componente de asimilación por impregnación del lenguaje musical en los métodos de transmisión cognitiva actuales, en los que la música de esta tradición académica es una lengua completamente extranjera para la mayoría de nuestros estudiantes. La enseñanza de la armonía en el teclado y la improvisación puede ser una herramienta muy efectiva para tal propósito, puesto que facilita la apropiación de estructuras complejas de la gramática musical que hasta nuestros días se han enseñado de manera casi por completo intelectual.

Este sistema de codificación de la gramática musical de los siglos XVII y XVII, llamado partimento, puede ser útil para lograr el objetivo de llevar la pedagogía de la "teoría musical", por tradición transmitida de manera racional, a un método de enseñanza que estimule más la intuición y los mecanismos naturales de adaptación y asimilación. 


\section{¿Qué es exactamente un partimento?}

A pesar de su estrecha relación con el bajo continuo, el partimento es del mismo tipo, pero de tal modo que no acompaña a ningún otro instrumento excepto a sí mismo. Es un bajo cifrado, pero con frecuencia hay ejemplos que no tienen ningún tipo de cifra. Es un bajo, pero también puede ser un soprano, un alto o un tenor. Aunque suele ocurrir que es la voz más grave, puede ser también un alto o un tenor y puede saltar de una voz a la otra dentro de la textura. Está escrito y concebido para la improvisación. Y, por último, aunque es un ejercicio, tal vez el más eficaz jamás diseñado para la enseñanza del estilo de composición de los siglos XVII y XVIII, también es una forma de arte en sí. ¿Qué es entonces un partimento? Es un bosquejo, escrito sobre un solo pentagrama, cuyo propósito principal es servir como guía para la improvisación y la composición en el teclado (Sanguinetti, 2012).

En la figura 1 se ofrece un ejemplo de un partimento de Giovanni Paisiello. Es notable la ausencia de cifrado numérico y la escasa información musical que tiene como para dar una idea de su realización.

Figura 1. Ejemplo de un partimento de Giovani Paisiello:

Regole per bene accompagnare il partimento 0

sia il basso fondamentale sopra il cembalo

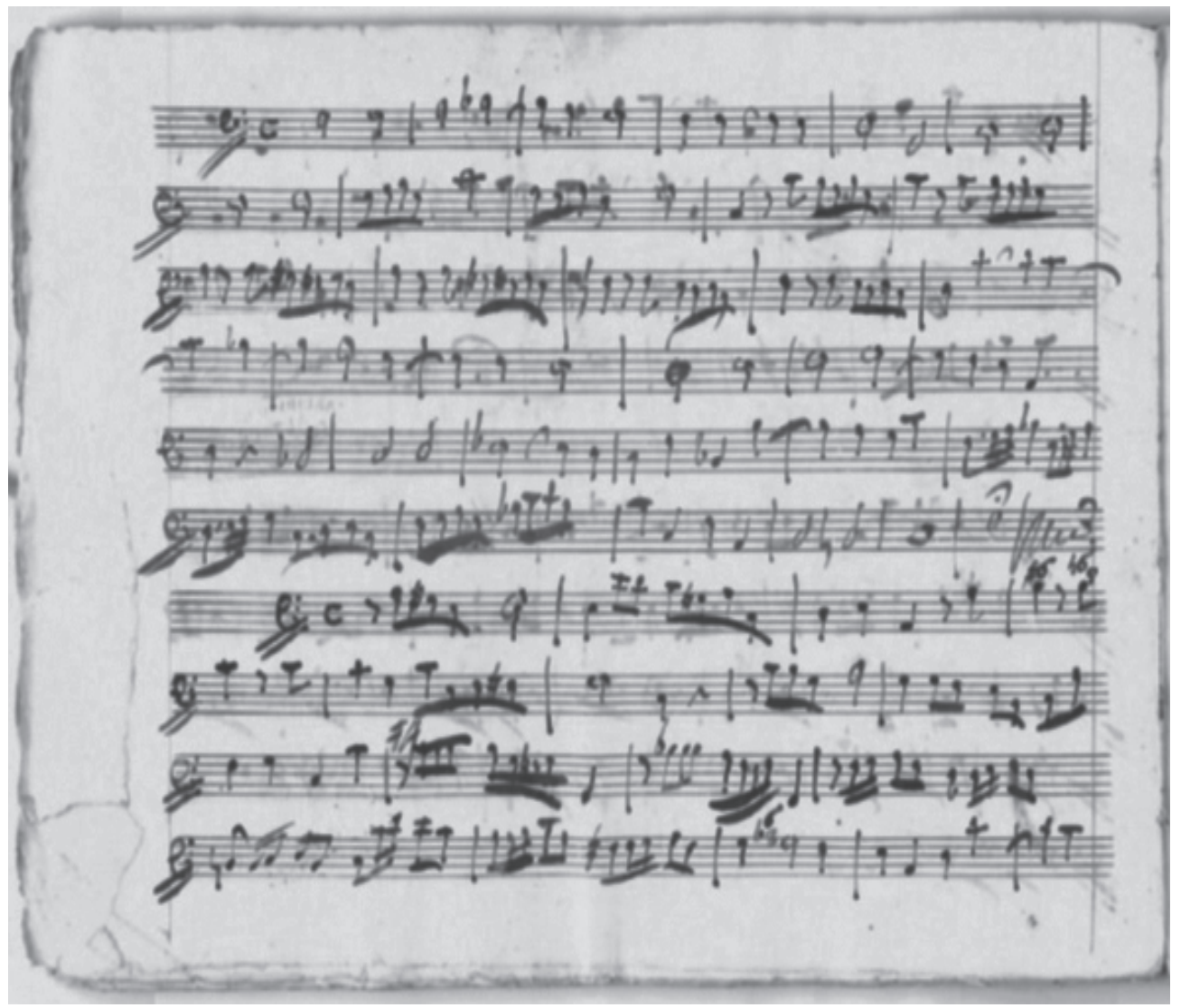




\section{Contextualización de la tradición del partimento al siglo XXI: enseñanza de la armonía práctica 0 en el teclado}

La propuesta pedagógica que aquí se presenta está basada en la experiencia vivida durante la Maestría en Teoría Musical en la Haute École de Musique de Genève $^{3}$ con el profesor David Chappuis.

En esencia, las clases de armonía práctica o en el teclado son la reminiscencia de la formación en partimento o bajo continuo que un músico profesional recibía en la Europa del siglo XVIII. A diferencia de ese siglo, en los conservatorios y universidades en los que se transmite la música académica, y en particular, en aquellos en los que se imparte dicha asignatura, ella no es el centro de formación sino algo accesorio para el estudiante y hace tan solo parte de su núcleo de materias complementarias a su disciplina principal. Por tal motivo no se puede profundizar mucho, dado que la armonía en el teclado es, en esencia, un arte en sí mismo. De acuerdo con mi propia experiencia y la de diferentes maestros, los estudiantes apenas aprenden los rudimentos básicos de la armonización en el teclado puesto que no tienen mucho tiempo de practicar lo suficiente. Además, la gran mayoría de la población es muy principiante en el dominio técnico del teclado.

Con la asignatura se busca abordar una gran cantidad de estilos de la historia de la tradición musical, desde los siglos XVIII hasta los albores del impresionismo en los siglos XIX y XX. El trabajo en la armonía en el teclado sirve, entonces, de herramienta para que el estudiante de música pueda comprender cómo se componía en varios períodos de la historia.

3 Escuela Superior de Música de Ginebra, Suiza.

\section{Siglo XVII-XVIII}

\section{Armonización en dos voces}

Figura 2. Ejemplo tomado de Nicolás Bernier

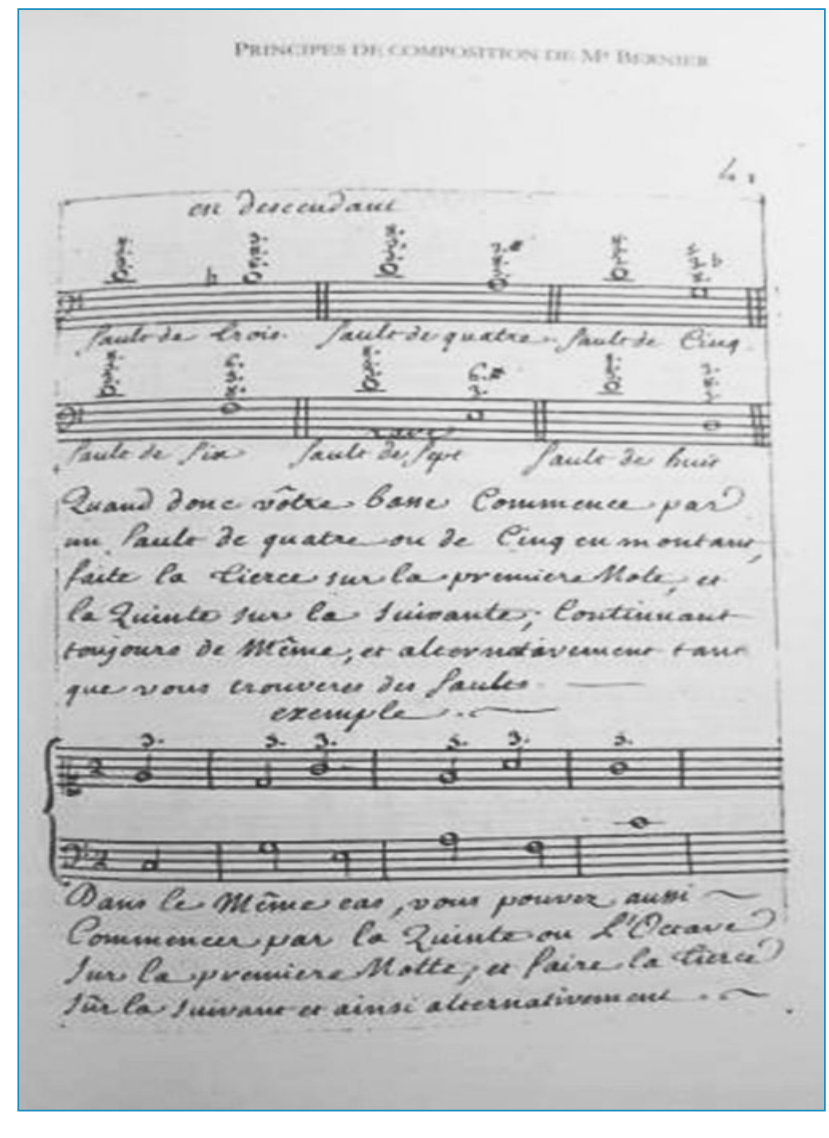

Fuente: Montagnier (2009, p. 41)

Como se aprecia en la figura 2, así como las colecciones de reglas (regole) de los maestros italianos, el método de Nicolas Bernier presenta primero las reglas de la armonía o contrapunto en dos voces (Montagnier, 2009).

Un principiante debe ir adquiriendo reflejos para armonizar en dos voces sobre un bajo no cifrado. Uno de los caminos por seguir es el método de Nicolas Bernier (Monagnier, 2009), que tiene un compendio de fórmulas de contrapunto mediante las que se explican los tipos de movimientos y cadencias.
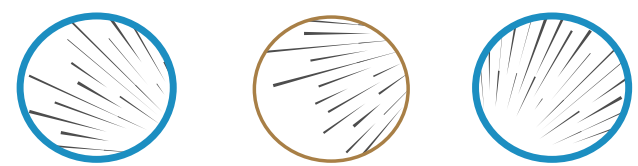
David Chappuis hizo todo un repertorio de movimientos melódicos y los utiliza en la enseñanza.

Figura 3. Ejemplos extraídos de armonía en dos voces del método de Nicolas Bernier utilizados en la clase de David Chappuis

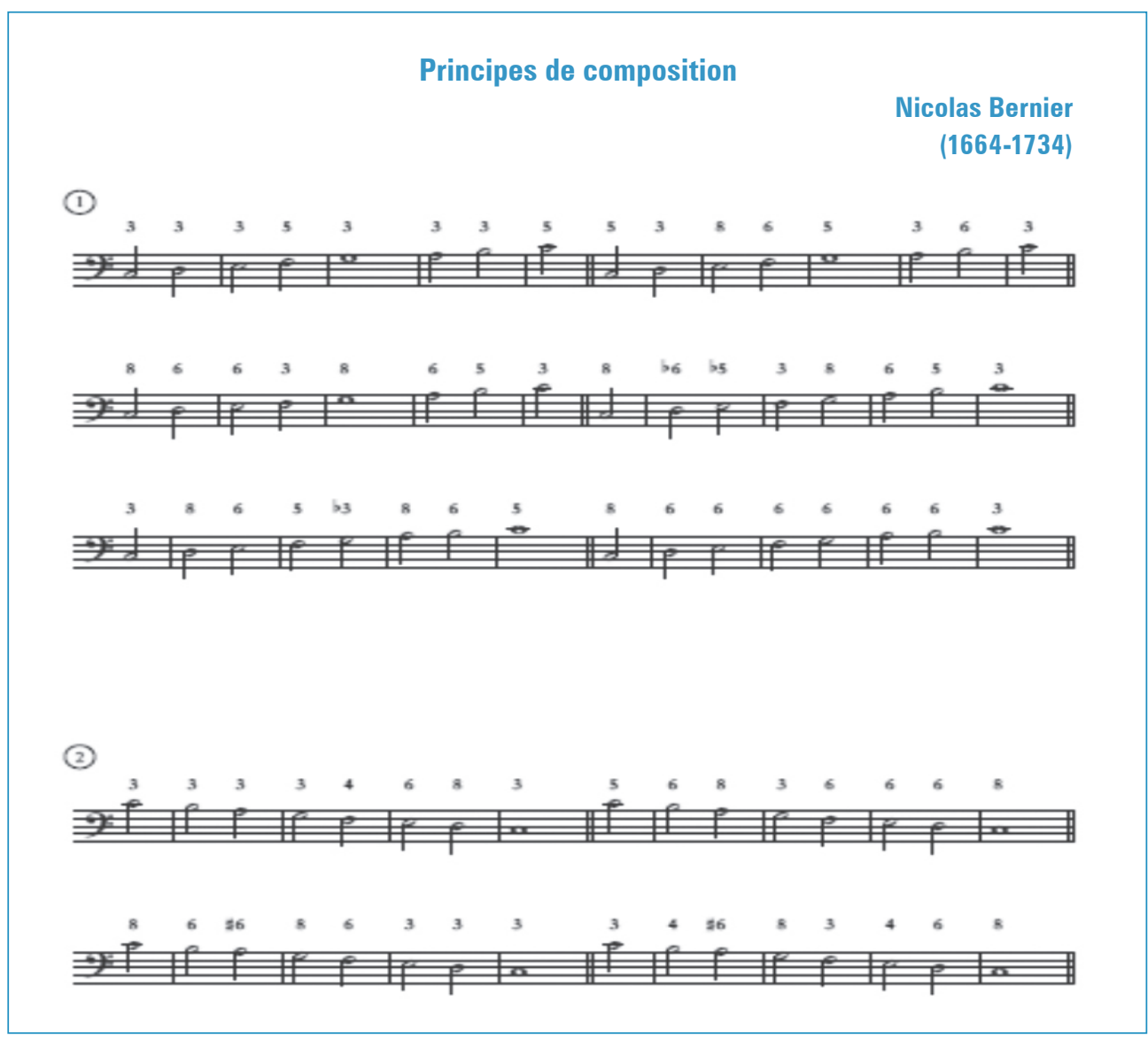

Fuente: Chappuis (2014-2015)

\section{Armonización en tres voces}

El paso siguiente es la armonización en tres voces. El mismo método de Nicolas Bernier cuenta con explicaciones sobre cómo proceder y David Chappuis tiene también todo un compendio de fórmulas para la armonización en tres voces sobre un bajo cifrado para el entrenamiento de los alumnos. Nótese la importancia que Bernier le da al dominio de la armonía en dos voces, dado que, apenas en la página 91 del mismo método (que tiene 111 páginas), empieza a abordar la armonización en tres voces. 
Figura 4. Introducción a la armonía de tres voces de Nicolas Bernier

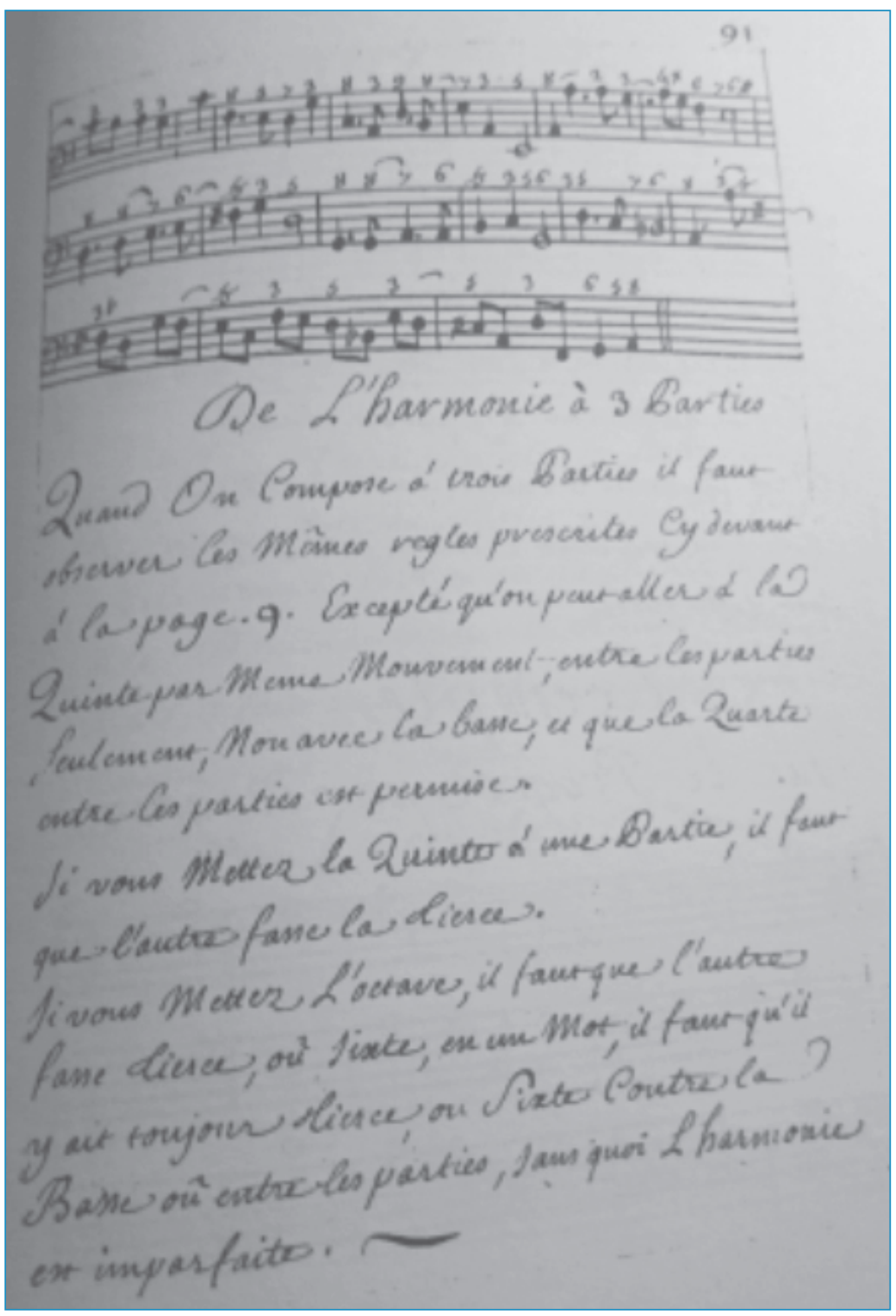

\section{Fórmulas cadenciales en tres voces}

Con David Chappuis, se trabaja sobre fórmulas cadenciales extraídas del repertorio de sonatas trio de Corelli. Debe lograrse el dominio, tanto en mayor como en menor, hacer trueques de las dos voces superiores y transportarlo por todas las tonalidades. Antes de pasar a la armonización en cuatro voces, es de vital importancia tener un dominio completo de la de tres puesto que es la base de cualquier estructura armónica y polifónica, pues la adición de una cuarta voz para completar la armonía es una destreza compleja que debe estudiarse por separado. La atención que se da a la correcta conducción de voces es fundamental. 
Figura 5. Serie de cadencias no cifradas

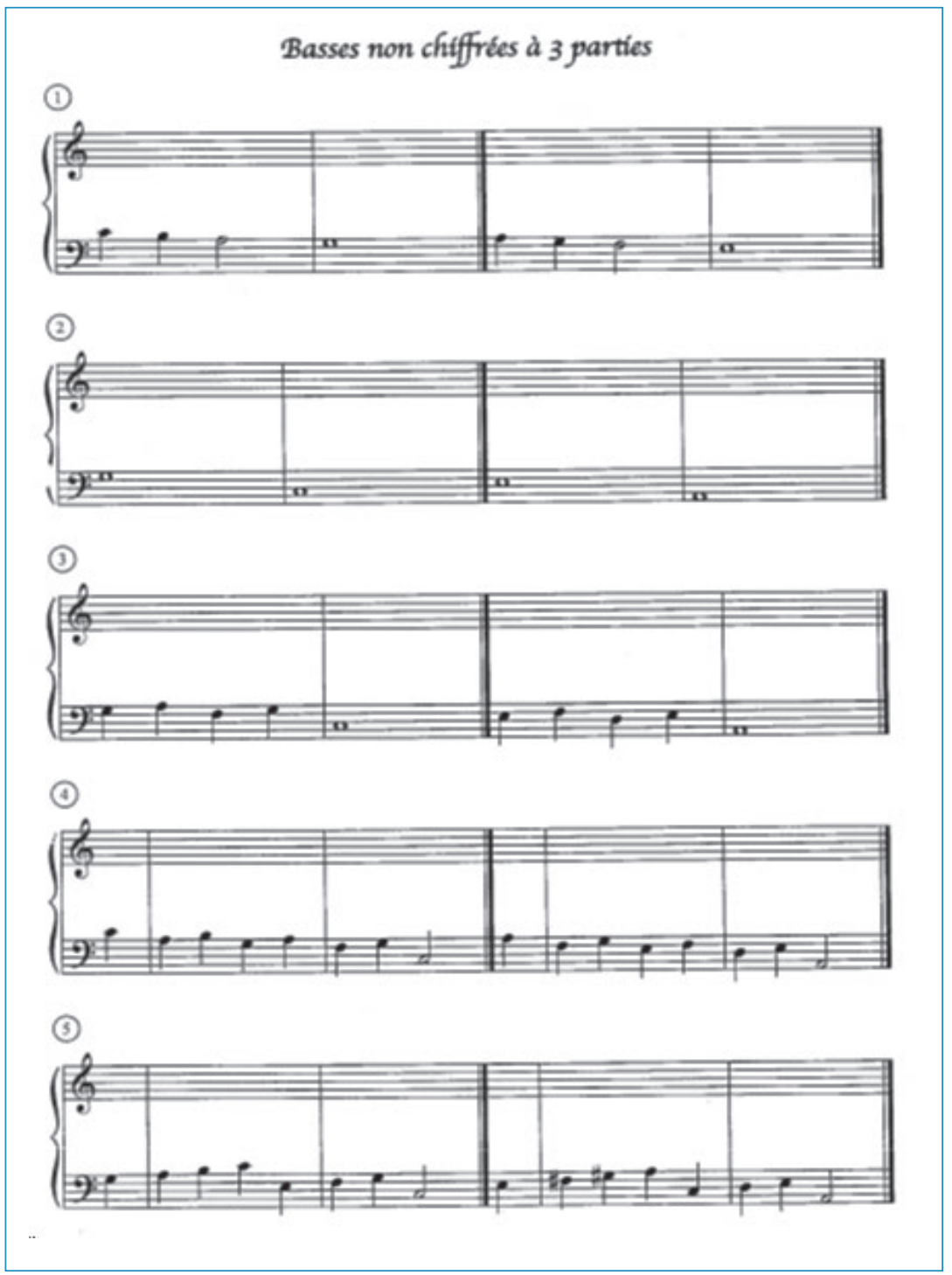

Fuente: Chappuis (2014-2015)

En la figura 5 hay una serie de cadencias no cifradas. El alumno debe encontrar la fórmula que corresponde a cada ejemplar. Puede servirse de un pentagrama vacío para escribir las líneas, si así lo necesita, para poder experimentar.
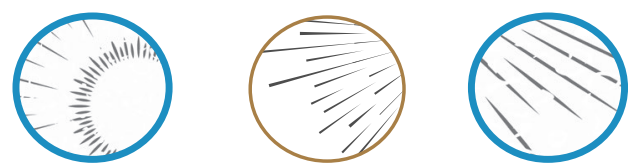
Figura 6. Compilación de armonización en tres voces del método de Nicolas Bernier

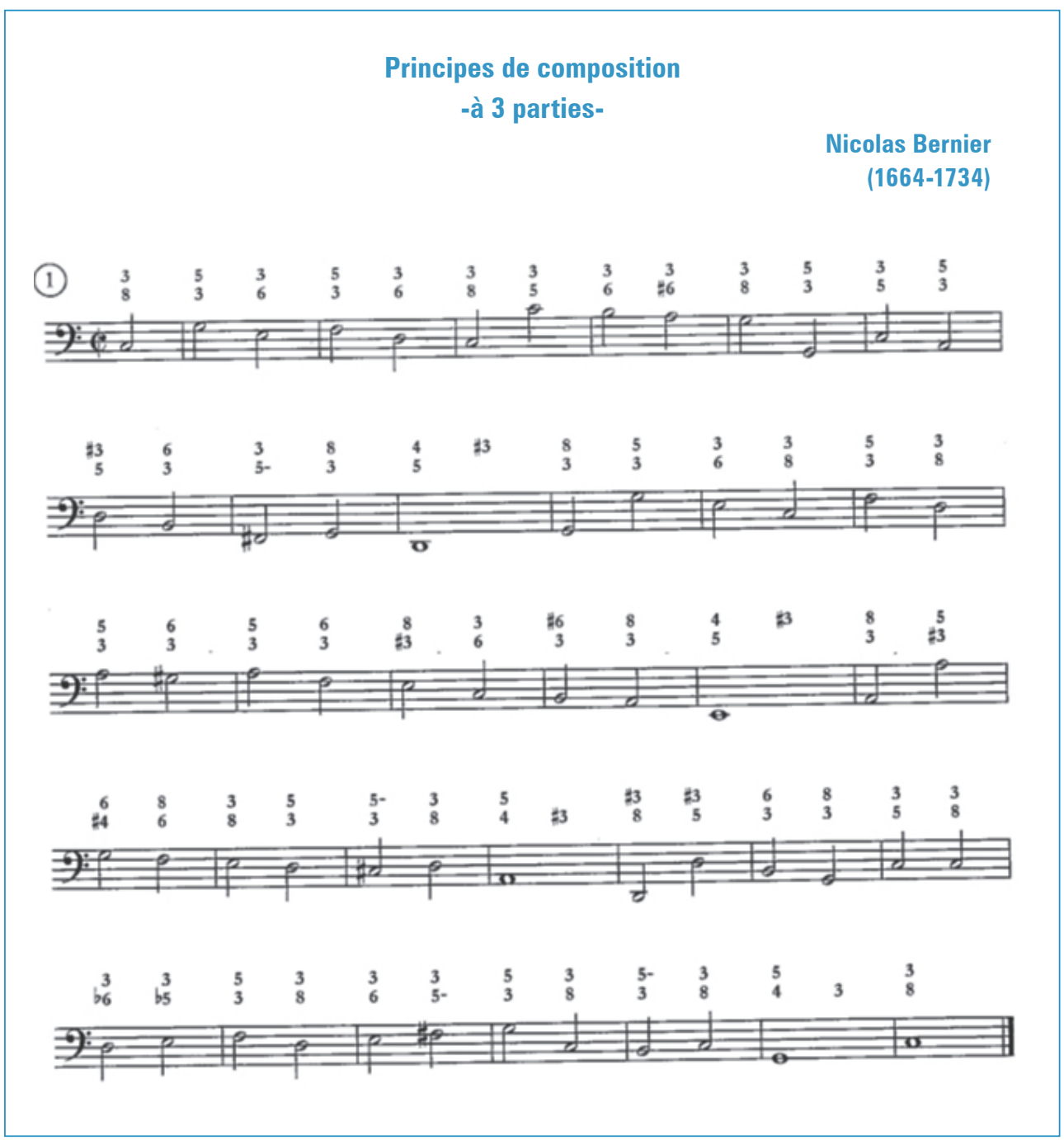

Fuente: Método Nicolas Bernier

\section{Trabajo sobre el repertorio}

Las sonatas en trío de Corelli son un gran ejercicio para lograr un dominio de la armonización en tres voces. El alumno debe encontrar la conducción correcta de ellas y deberá resolver ciertos acertijos para cuidarla. Es importante confrontar la propuesta que el estudiante hace con lo que el compositor escribió, para nutrir la búsqueda con nuevas ideas. 
Figura 7. Trío sonata No. 1, op. 3, Arcangelo Corelli

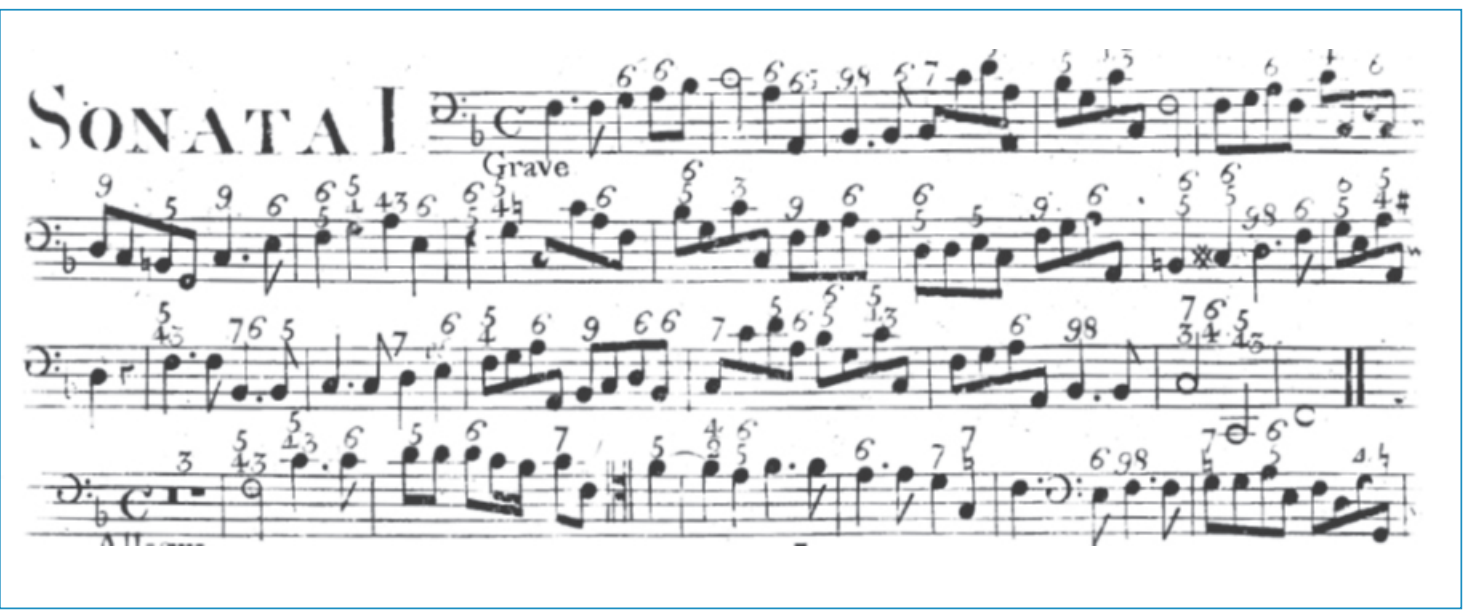

Fuente: (Petrucci Music Library, 2016,pg.2)

Regla de la octava

Figura 8. Regla de la octava

\section{Regle de L'Octave}

Les chiffres

1. En majeur

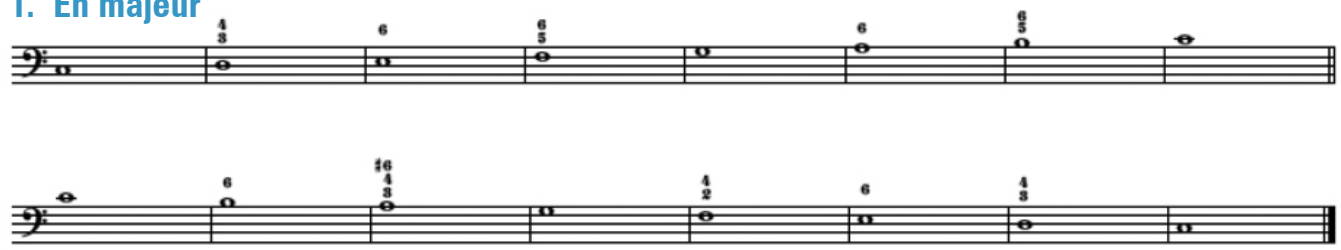

2. En mineur
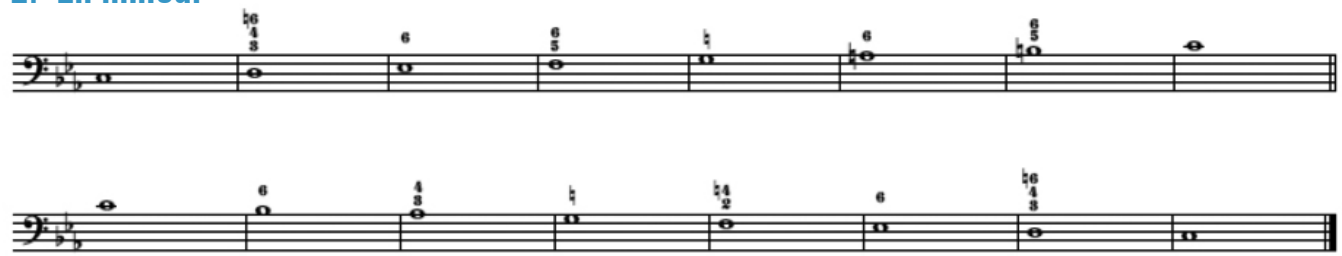

Fuente: Chappuis (2014-2015)

El estudiante deberá aprender y ejercitar la regla de la octava. 
Para familiarizarse con este rudimento básico, habrá de transportar la escala armonizada a diferentes tonalidades, ejercitarse en tocarla en distintas disposiciones en la mano derecha y también aprenderla solo con la mano izquierda.

\section{Introducción a la armonización en cuatro voces}

Es el siguiente nivel, luego de haber logrado cierta maestría en las etapas anteriores ${ }^{4}$. Se recomienda el método de Nicolas Bernier. De igual manera, Chappuis cuenta con toda una compilación de cadencias basadas en dicho método para la práctica.

Figura 9. Compendio de fórmulas para cuatro voces de David Chappuis (fórmulas de acordes ${ }_{5}{ }^{6}, 7 \mathrm{y}_{2}{ }^{4}$ puestas en contexto)

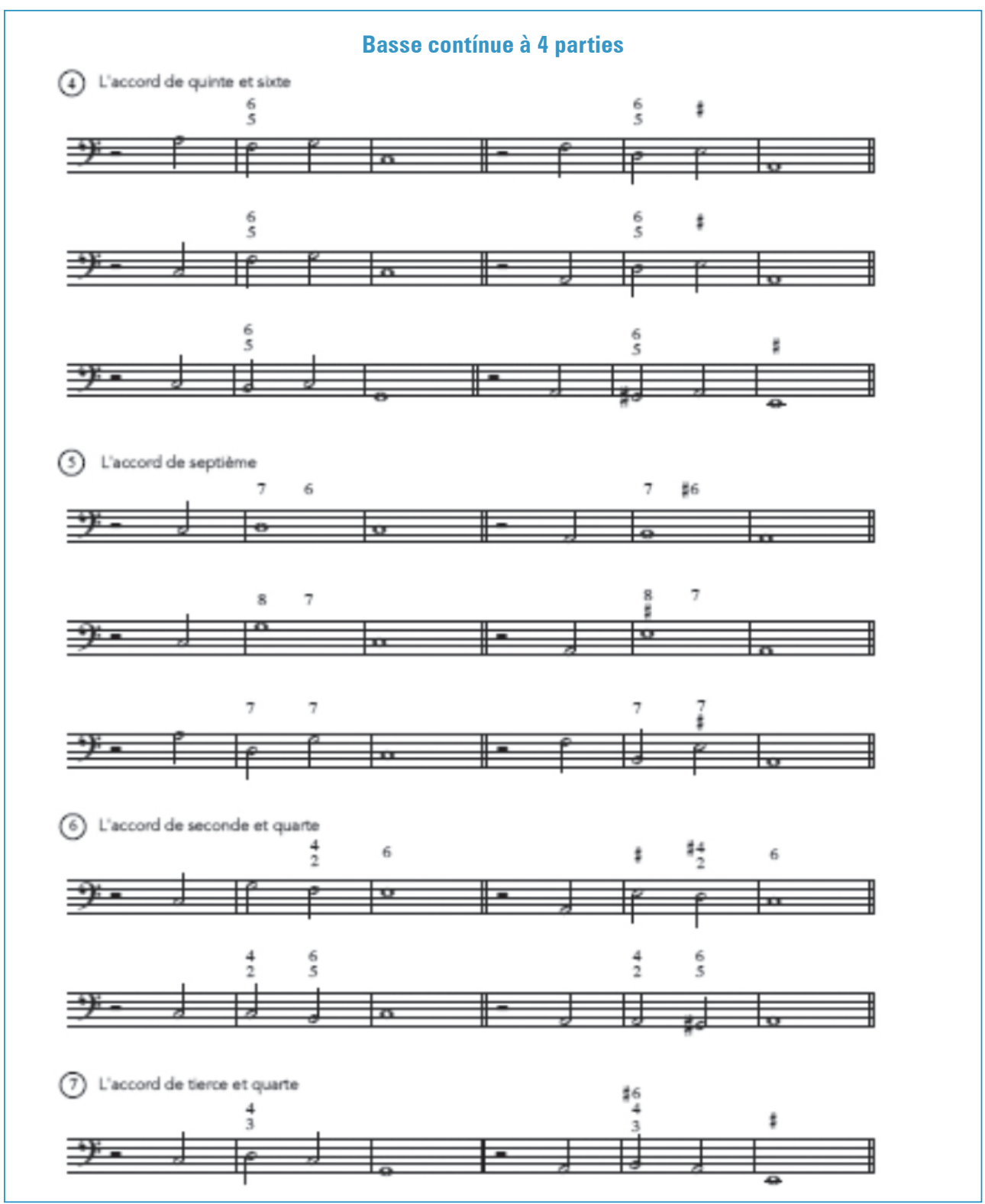

Fuente: Chappuis (2014-2015)

4 Personalmente yo no logré llegar a esta etapa durante mi último año de armonía práctica. El trabajo para lograr el dominio de la armonía en tres voces es largo. 


\section{Disminución}

Todas las etapas mencionadas hasta ahora son solo el esqueleto de la estructura musical que se está recreando con el bajo cifrado. La disminución (en su sentido prístino de figuración) está reservada para estudiantes avanzados en el arte del partimento y el bajo continuo. Si la meta es en realidad ser un "partimentista", un improvisador o un gran acompañante al bajo continuo, la inclusión de la disminución al trabajo es esencial. Además, la musicalidad debe ser el centro del aprendizaje y no se debe limitar a simplemente tocar encadenamientos de acordes. Llegar a este nivel requiere dedicación total. Se puede suponer que el alumno estaría listo para abordar también la fuga, que es un universo aparte.

\section{Siglo XIX: Romanticismo}

\section{Encadenamientos y modulaciones típicas}

Para introducirse en la estética del siglo XIX se empieza por abordar las cadencias, para hacer el enlace con el siglo XVIII, pero se agrega un elemento más: la modulación. David Chappuis propone cuatro tipos de modulaciones. El alumno debe ejercitarse y dominar cada una, tanto en mayor como en menor. Se sugiere que trabaje en el siguiente orden:

1. Modulación directa: sobre el séptimo grado de una tonalidad dada se realiza un acorde de quinta-sexta $\left({ }_{5}^{6}\right)$. El bajo resuelve por semitono al primer grado. Luego, el bajo desciende una quinta hacia el cuarto grado, en el que se hace un acorde de ${ }_{5}^{6}$, para ir luego al quinto en un acorde, sea $\mathrm{de}_{4}{ }^{6} \mathrm{O}$ de ${ }_{4}^{5}$, que se resuelve después en un acorde perfecto, y completar la cadencia con un acorde perfecto sobre el primer grado.

Figura 10. Modulaciones

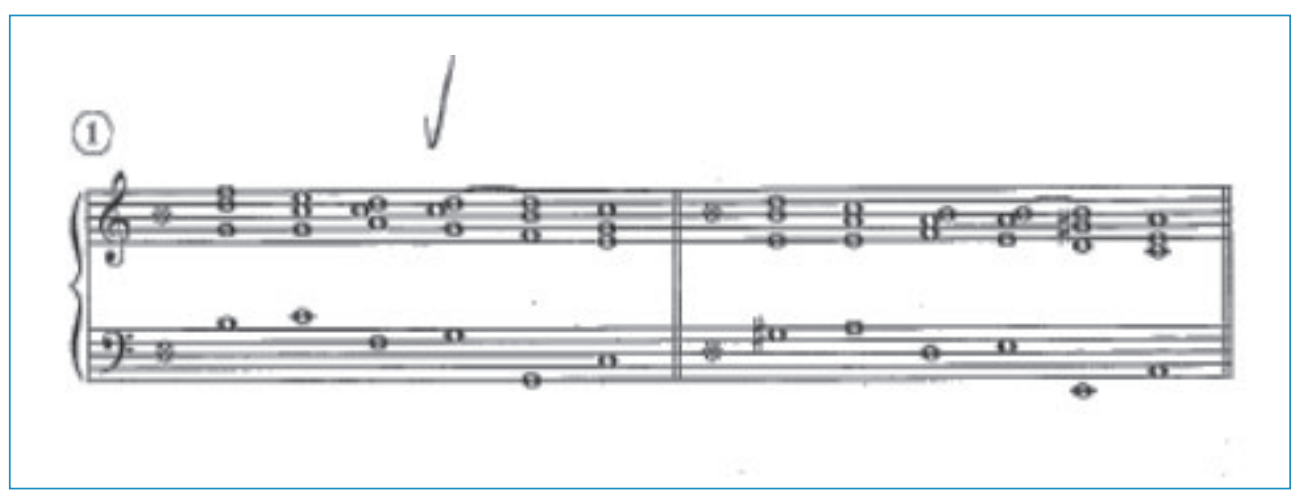

Fuente: Chappuis (2014-2015) 
2. Modulación que pasa por el sexto grado: se realiza una modulación directa hacia el sexto grado. El bajo luego hace un movimiento de tercera bajando al $4^{\circ}$ grado para acabar luego en una cadencia compuesta: acorde ${ }_{4}^{6}$ sobre el quinto grado, que resuelve a un acorde de $7^{\mathrm{a}}$, y éste a un acorde perfecto.

Figura 11. Modulaciones

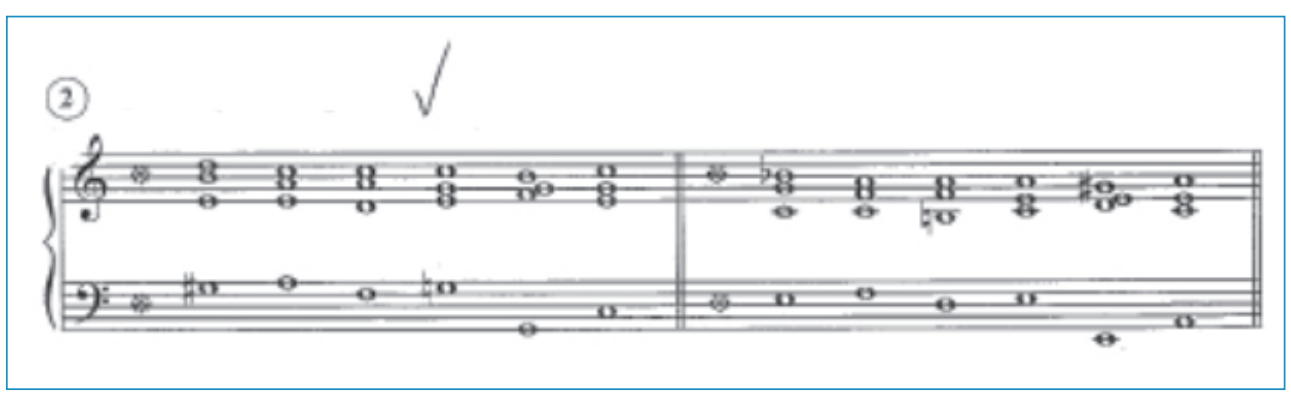

Fuente: Chappuis (2014-2015)

3. Modulación por el segundo grado: el principio utilizado para modular al sexto grado se utiliza también para el segundo, si se tiene en cuenta que el último solo funciona en mayor. En menor hay que hacer algunos ajustes. El alumno debe utilizar el acorde de sexta napolitana, que funciona como un segundo grado más estable en el modo menor. En este caso se realiza una modulación directa hacia el segundo descendido, para llegar a un acorde perfecto. Se hace un movimiento de bajo para formar un acorde de sexta con las mismas notas en la mano derecha y se hace una cadencia compuesta ${ }_{4}{ }^{6}$ - acorde de séptima, para resolver a la tónica en un acorde perfecto.

Figura 12. Modulaciones

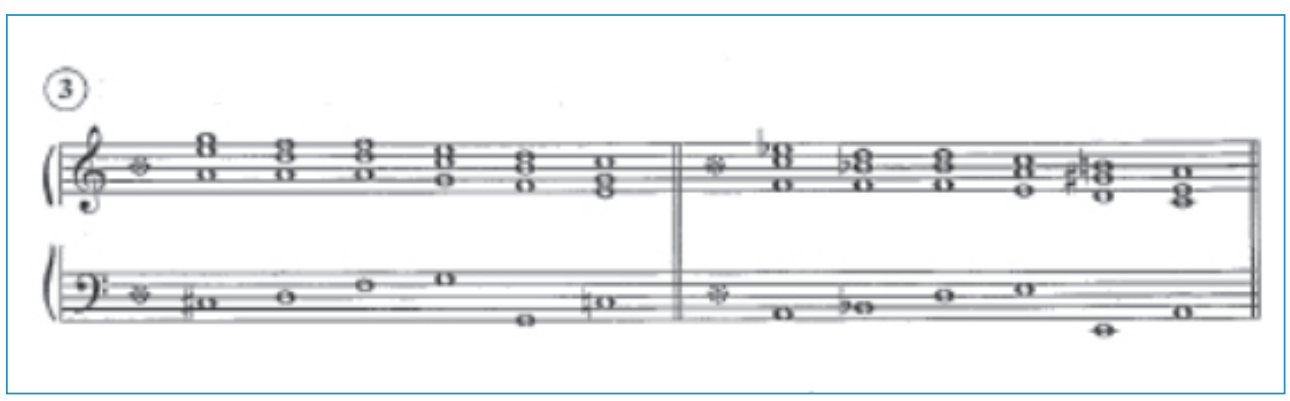

Fuente: Chappuis (2014-2015)

4. Modulación por el cuarto grado (e introducción al acorde de séptima disminuido): el principio utilizado para modular será el mismo; en este caso, se tendrá en mente el cuarto grado, con el acorde ${ }_{5}^{6}$ que formará una modulación directa por medio de un movimiento de semitono en el bajo. Aquí se introduce un nuevo acorde por cromatismo. El bajo sube a la sensible del quinto grado y se construye un acorde disminuido con séptima sobre la sensible para llegar a la cadencia ${ }_{4}{ }^{6}-7 \mathrm{y}$ acorde perfecto del primer grado.
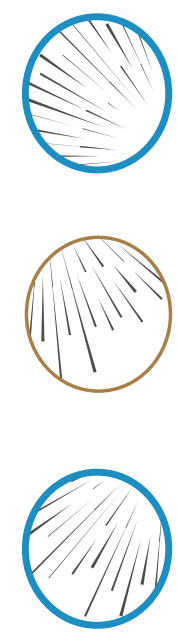
Figura 13. Modulaciones

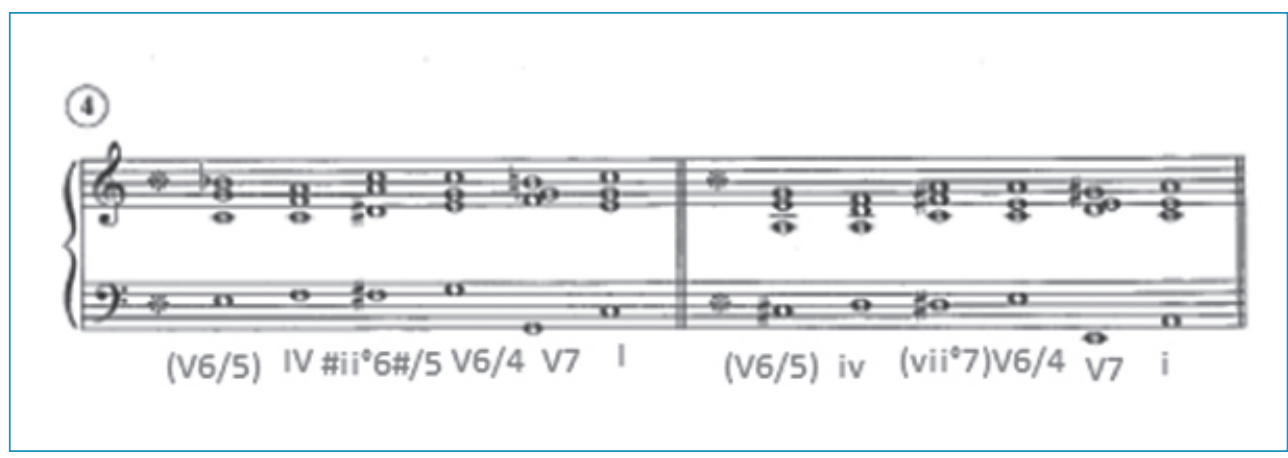

Fuente: Chappuis (2014-2015)

\section{Cromatismos y modulaciones lejanas con los acordes disminuidos y de sexta aumentada}

Una vez que el alumno tiene soltura con las modulaciones de base se introducen las modulaciones por cromatismo hacia tonalidades lejanas en el círculo de quintas. El principio consiste en saber a cuál grado de la tonalidad se piensa modular, para insertar una interdominante por medio de diferentes movimientos en el bajo, sea una sensible inferior o superior.

1. En cuanto al acorde de vii ${ }^{\circ}$ se puede pensar en la sensible de la dominante o un tono por encima de la misma.

Figura 14. Modulaciones

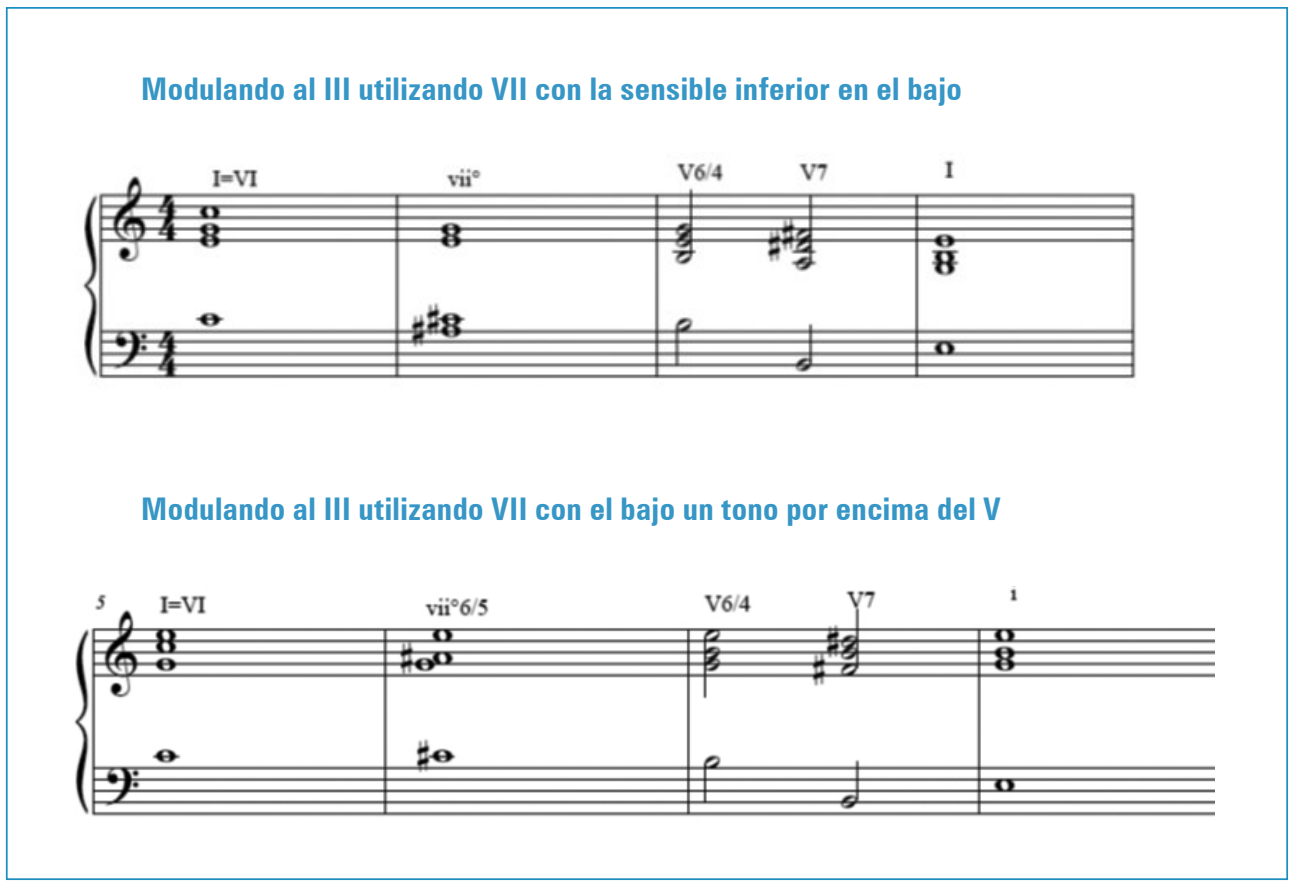

Fuente: Chappuis (2014-2015) 
2. Con el acorde de sexta aumentada hay un principio sencillo. Primero, se debe pensar una tonalidad lejana. Por ejemplo, si se desea modular de do mayor a la bemol mayor, el estudiante debe pensar un acorde de dominante $\left(\mathrm{V}_{7}\right)$ un medio tono por encima del quinto de la tonalidad a la que se va a modular. Entonces, en lugar de ir a la menor, el bajo resolverá medio tono hacia abajo, para llegar a la dominante de la bemol mayor, como en este caso. El alumno, en primera instancia, no ha de preocuparse por refinar la diferencia entre las diferentes sextas aumentadas (francesa, italiana, alemana) ni tampoco de la ortografía de las mismas. Basta con entender este primer principio con la sexta aumentada alemana. Después se pueden incorporar las otras dos.

Figura 15. Modulaciones

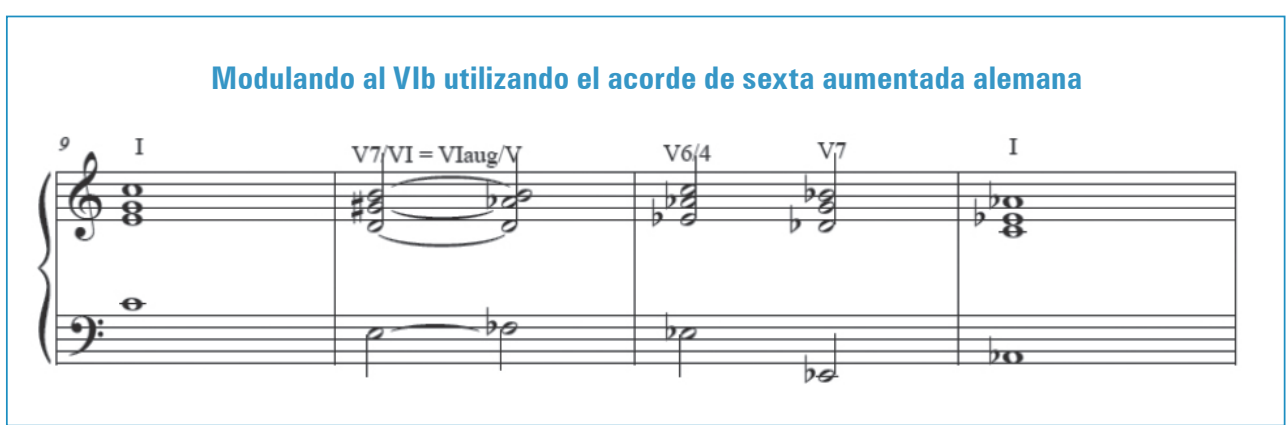

Fuente: Chappuis (2014-201)

\section{Improvisación de los encadenamientos con modulaciones}

Una vez adquiridos los reflejos para diferentes tipos de encadenamientos y modulaciones es tiempo de forjar un sólido arsenal al ponerlo todo junto. El maestro retará al alumno, para lo que le señalará la tonalidad de partida y la de llegada, y el pupilo deberá expresar lo que sabe sobre encadenar acordes en ese camino. Podrá utilizar modulaciones al segundo grado, al sexto, al cuarto, introducir acordes disminuidos, de sexta aumentada, napolitanos, podrá "alejarse de casa", viajar por tonalidades lejanas y volver triunfante, para terminar con una gran cadencia perfecta, que se escapa de manera sorpresiva con una cadencia rota para volver con calma a la tónica.

\section{Introducción a la improvisación}

La iniciación a la improvisación o inventiva melódica en el estilo romántico puede hacerse sobre una progresión armónica sencilla compuesta con anticipación, en tempo de vals lento. Incluso si el alumno no es tecladista, es importante, de todas formas, animar a los estudiantes a desarrollar la inventiva, así sea en un nivel básico. El maestro le puede aportar progresiones sencillas, en primera instancia. Se sugiere empezar con simples cadencias. Luego podrá extraer los acordes de una pieza corta, un vals o una mazurca, y ponerlos solo a la mano izquierda en una hoja y dejar la mano derecha vacía en el pentagrama. El alumno podrá entonces hacer idas y venidas entre 
escritura e improvisación para refinar su inventiva melódica. Después el maestro le mostrará la pieza original, para confrontar la versión propia con la del compositor y así sacar conclusiones y admirar el genio del creador de la pieza. Es el caso de una mazurca de Glinka en do menor.

Figura 16. Un fragmento trabajado en clase

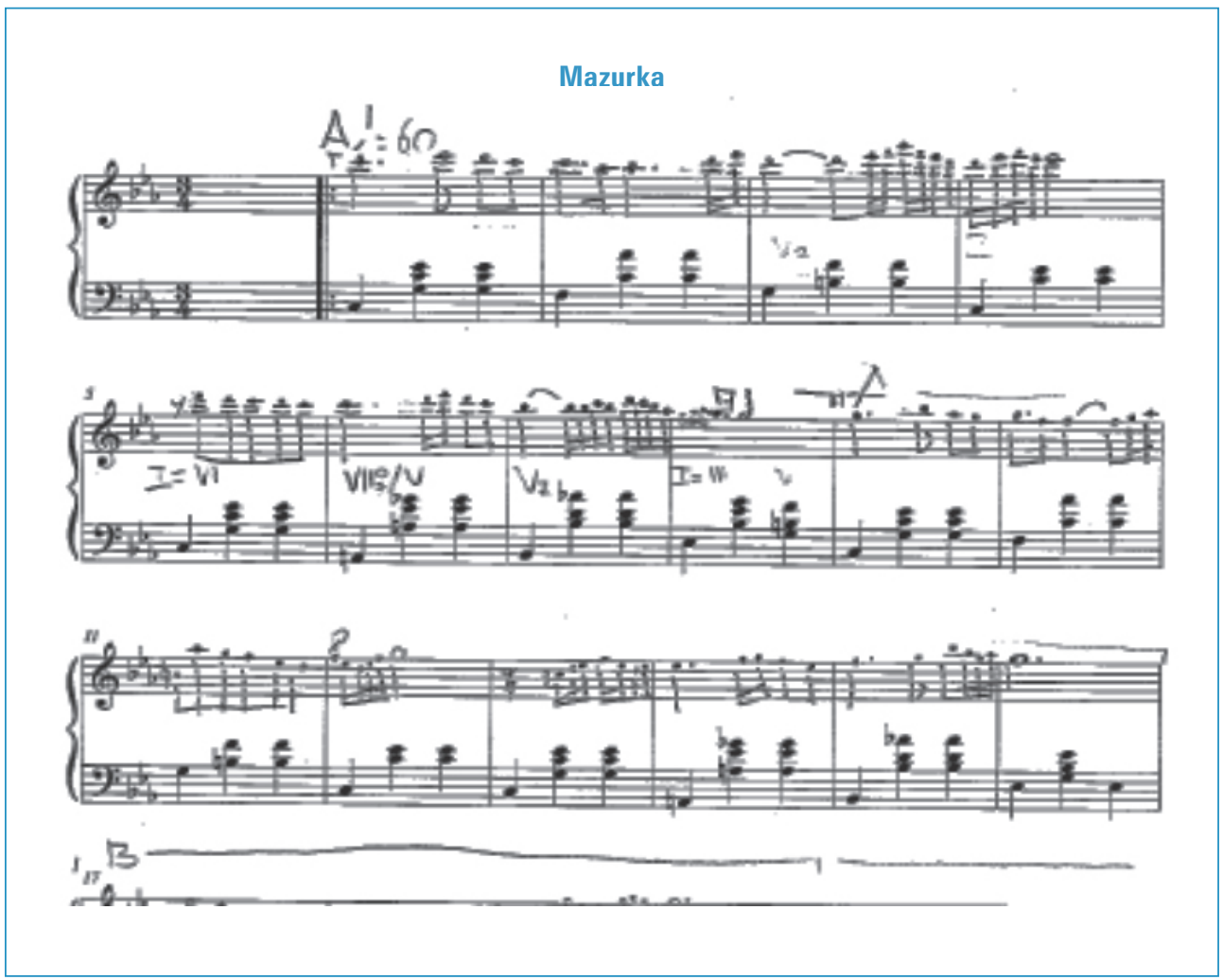

Fuente: Chappuis (2014-2015)

En la figura anterior se observa que en la mano izquierda solo hay acordes mientras que en la mano derecha se deja un espacio para que el alumno anote algunas ideas, para hacer idas y venidas entre improvisación y composición.

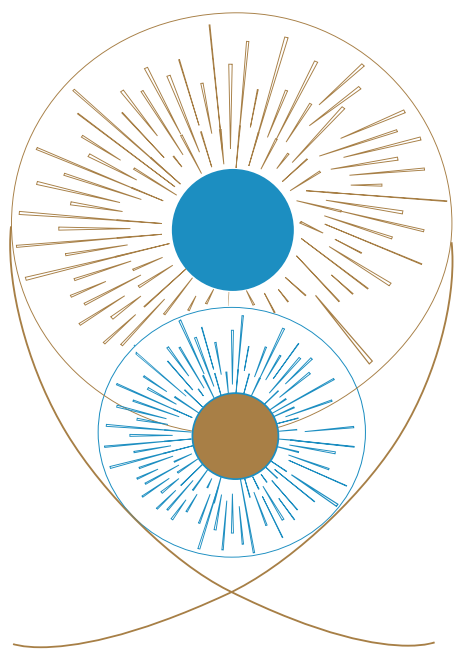


Figura 17. Mazurka en do menor de Glinka, versión original

NA3YPKA

MAZURKA

(1843?)
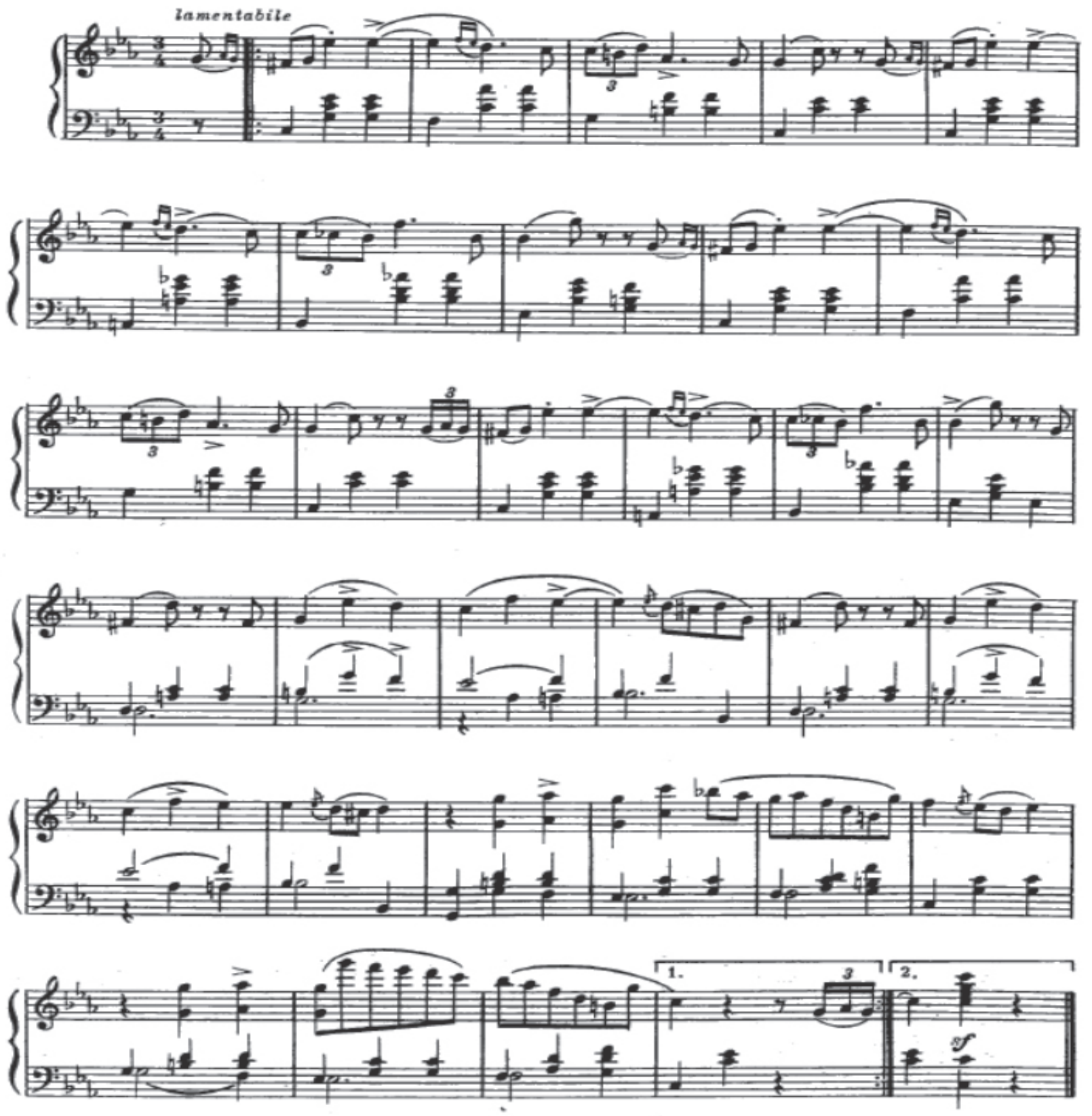


\section{Improvisación melódica sobre la modulación}

Una vez que el alumno tenga cierta soltura con la creación de todo tipo de modulaciones puede entonces entrenarse en improvisar melodías por encima de un camino armónico. Esta etapa implica que se trabaje con rigor sobre planes armónicos con modulación compuestos con anticipación; la meta aquí es reforzar la inventiva melódica. Por consiguiente, es una oportunidad para trabajar cuestiones de estilo: se enfatiza, por ejemplo, en las apoyaturas cromáticas, tan características del Romanticismo. En un primer nivel, la métrica y el compás no han de preocupar, para facilitar el aprendizaje: o sea que los primeros intentos serán una serie de acordes en negras en compás ad libitum y los cambios armónicos se darán cuando así lo sienta el estudiante, según el contorno de la melodía. Después se agrega la dificultad de la métrica: comenzar con tempos binarios y luego ternarios. Más adelante se puede probar la improvisación sobre un estilo de danza particular: un vals, un minué, una polka, una mazurca, entre otras posibilidades. A medida que se avanza, pueden irse refinando cuestiones pianísticas, como el uso que se da a todo el registro del teclado, el contrapunto, el virtuosismo de la melodía, etc.

\section{Improvisación integral con modulaciones}

Una vez integrada la melodía, se puede probar, entonces, realizar temas con variaciones o piezas de carácter ${ }^{5}$, fantasías, nocturnos. Se debe buscar que la modulación surja como un recurso expresivo espontáneo y que no se sienta forzada. También se refina la retórica mediante la improvisación sobre afectos diversos. El estudio de las obras escritas por los grandes maestros (Beethoven, Brahms, Chopin, Lizst, Wagner, ...) puede considerarse como nivel gradus ad parnassum de la improvisación en estilo romántico y requiere también un grado de entrega y de trabajo casi exclusivos.

\section{Siglo XIX-XX: Impresionismo}

Es importante integrar al trabajo de armonía en el teclado la estética impresionista, que tiene como estandartes a Claude Debussy y Maurice Ravel, por la gran influencia que tuvieron en la modernidad musical. Estos estilos utilizan acordes conocidos en el contexto tonal funcional del siglo XIX, además de otros construidos a partir de intervalos diferentes a las terceras superpuestas, lo que los despoja de su sintaxis y su semántica, en pro de una búsqueda netamente estética personal, como en el caso de Debussy. Así, se tiene a disposición todo un arsenal de acordes con disonancias no preparadas por movimientos contrapuntísticos, como los acordes con sexta agregada, acordes mayores y menores con séptima sin preparación, acordes con séptima, novena, undécima, decimotercera, acordes aumentados, etc... Dichos acordes hacen parte de una nueva paleta de colores y sus encadenamientos se rigen simplemente por la conducción de voces.

5 Charakterstück, como se conoce el término en alemán. 
Trabajar esta estética de forma metódica y enseñarla a los alumnos a partir de lo concreto, sin necesidad de acudir a excesos intelectuales, no es fácil, puesto que cada pieza de los compositores llamados impresionistas es muy diferente una de otra. Como es obvio, tienen trazos comunes, pero extraer un sistema que resuma el lenguaje armónico parece ser muy complicado.

No obstante, hubo una tradición que tomó en préstamo muchos elementos del vocabulario armónico de los mencionados compositores y casi llegó a crear un sistema estandarizado que nos permite entender el vocabulario de los maestros franceses de finales del siglo XIX para construir puentes entre dos de los universos musicales más influyentes de Occidente en la modernidad: la tradición europea y el jazz. La tradición del partimento encuentra su equivalente moderno en el cancionero estadounidense, conocido también como real book, que es una antología de las obras más famosas del jazz, casi todas sacadas de la música popular de Estados Unidos, en su mayoría de la primera mitad del siglo XX. Las partituras de ese cancionero o real book son una síntesis muy simplificada de canciones populares. No tiene ninguna especificidad tímbrica y tan solo contiene un sistema de pentagrama (al igual que el partimento), en el que está únicamente escrita la melodía de la canción, junto con el cifrado literal numérico. Las canciones de jazz, conocidas con el término standards, son mucho más simples en estructura que la mayor parte de colecciones de partimento, con temas de blues de 12 compases y canciones de 16 o 32 compases y, así como con los bassi ostinati, se utilizan como base para la improvisación de variaciones, en las que el tema musical es tan solo un medio sobre el cual se desarrolla el propio lenguaje musical.

Las colecciones de real book se escriben en formato de lead-sheet ${ }^{6}$, que es un plan de composición, como el partimento antiguo, utilizado por los compositores y arreglistas en los siglos XX y XXI, en el que sólo se escribe la melodía, con el cifrado de los acordes encima, en letras mayúsculas (A, B, C, D, E, F, G), sin necesidad de escribir los acordes de piano completos, a menos que se busque plasmar un acorde muy difícil de cifrar de manera estándar. A diferencia del lead-sheet y del partimento, la partitura de real book o de cancionero es una síntesis de una obra ya existente, que parte, por lo general, de una grabación.

Así entonces, el lead-sheet, el cancionero, o el real book, son muy útiles para sistematizar la enseñanza del lenguaje armónico de los compositores impresionistas, al menos en sus rudimentos. Para ahondar en toda su complejidad sí es necesario sumergirse en el análisis de su repertorio. Además, dado que el jazz no solo se basó en el lenguaje armónico impresionista, sino también en toda la tradición heredada desde el siglo XIX, la práctica del lead-sheet sirve también para entender gran parte del repertorio romántico.

6 Esta expresión podría traducirse como "planilla conductora" o "planilla guía". 


\section{Familiarización con el cifrado del jazz}

El primer paso para introducir a los estudiantes a los lead-sheets es enseñarles los códigos de cifrado. A continuación se muestra una gran cantidad de formas de cifrado que el maestro tiene a disposición, que señala con precisión cómo ha de realizarse cada acorde. Lo que varía es la disposición en el teclado. Hay que notar que es precisamente este elemento, la disposición de los acordes en el teclado, lo que es difícil de explicar en un sistema teórico complejo y, así como la realización del partimento antiguo, queda sujeta a la transmisión oral y al gusto del intérprete. El maestro habrá de comenzar por lo más básico: los acordes perfectos, mayor y menor; luego los acordes en inversión; más tarde puede agregar las disonancias de séptima de dominante, de sexta agregada y acordes mayores y menores con séptima, mayor y menor, en su orden. A medida que se avanza se pueden ir introduciendo los acordes disminuidos, aumentados, con novena, oncena, trecena, y así sucesivamente, todo en paralelo a medida que se avanza en el repertorio, mediante la ampliación del vocabulario que el mismo va exigiendo.

Figura 18. Catálogo de posibilidades de cifrado utilizado en los lead-sheets

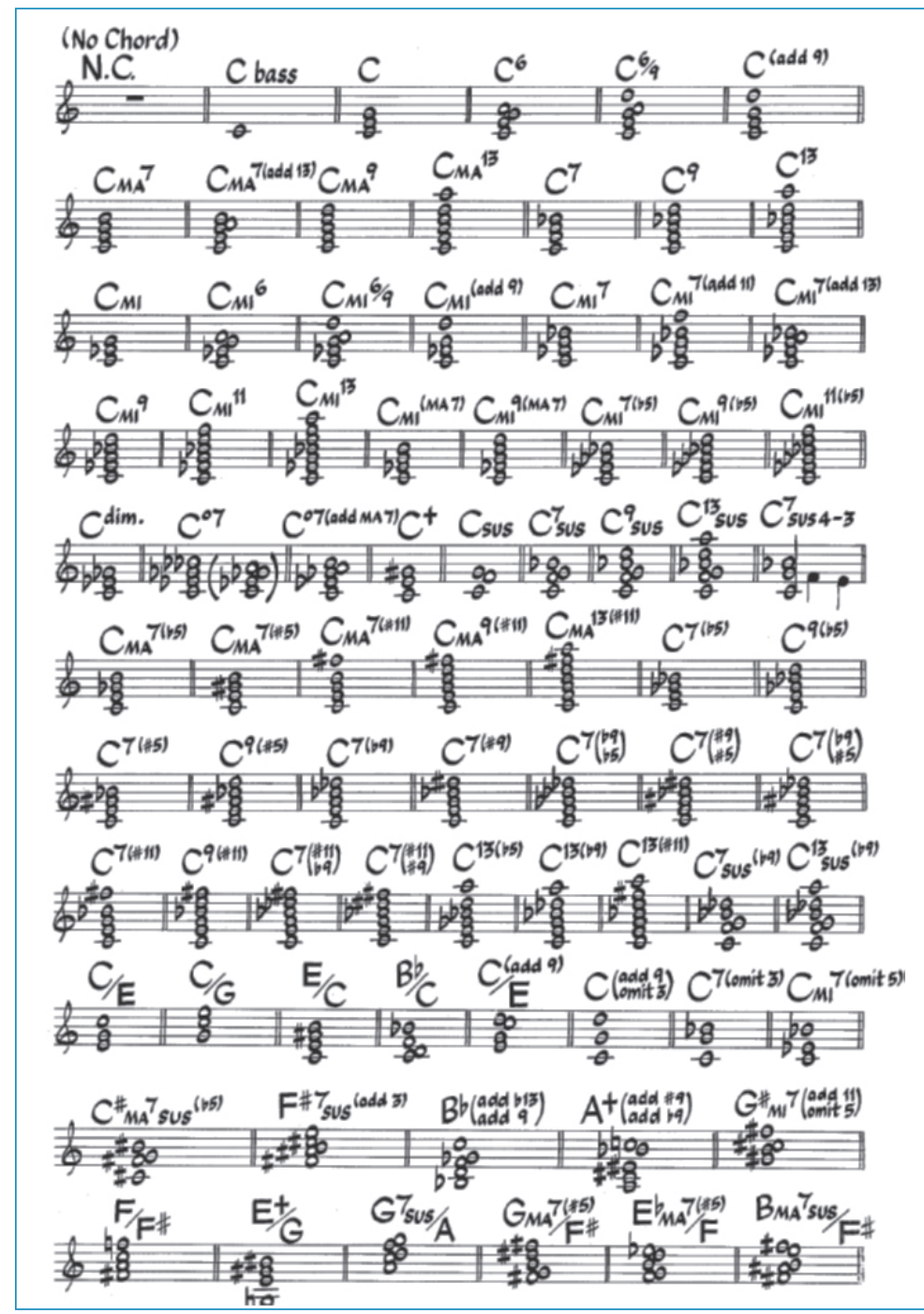

Fuente: Sher Music Co., (1988) 


\section{Armonización de standards de jazz a tres voces}

Una vez adquirida cierta familiaridad con el sistema de cifrado y la realización de acordes de jazz, el sistema de apropiación de la armonía es exactamente el mismo que el que los maestros del siglo XVIII proponen, como lo muestra Rudolph Lutz (2010), también en su metodología de la Schola Cantorum Basiliensis. Tomemos el ejemplo del tema Someday my Prince will come.

Figura 19. Some day my Prince will come, composición de Frank Churchill, parte del repertorio standard del jazz
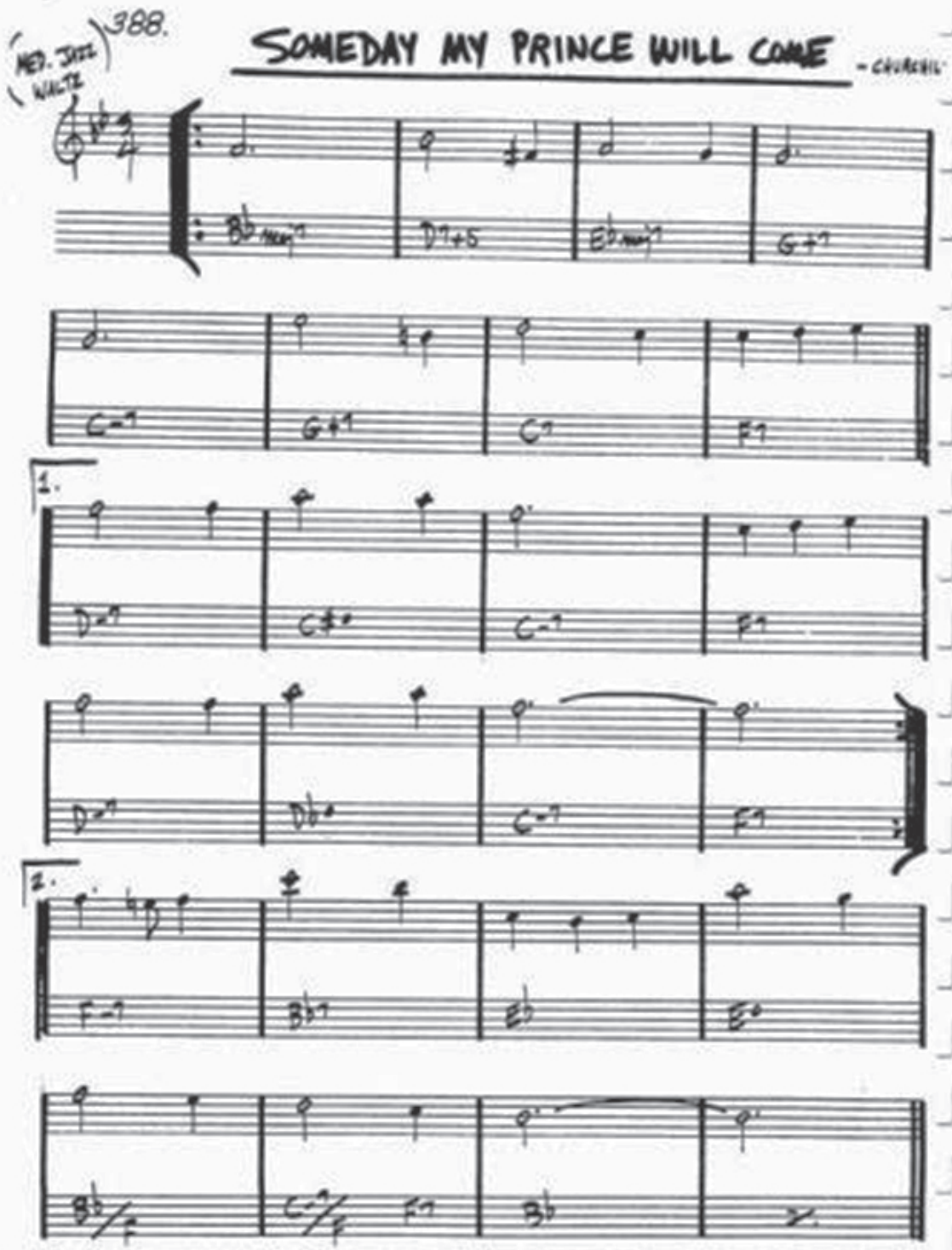

Miloe Dowe. "Con...t. 4 D..." 
1. Realización de la armonía sin melodía: el primer paso consiste en encontrar la armonía y su correcta conducción de voces. Al inicio se debe armonizar a tres voces, solo con las notas diacríticas de cada acorde, más conocidas en el jazz como guide tones. Se toca la fundamental del acorde en el bajo (la mano izquierda), la tercera, y la séptima en la mano derecha. Es el mismo principio de contrapunto a tres voces que los compositores del siglo XVIII seguían, utilizado también en los métodos de armonización de jazz del siglo XX, como el de Mark Levine (1989). Esto dará una idea de cómo funciona la armonía y ayuda al alumno a apropiarse de la pieza. Transponer la pieza por varias tonalidades es altamente recomendado.

Figura 19. Someday my Prince will come, armonización básica

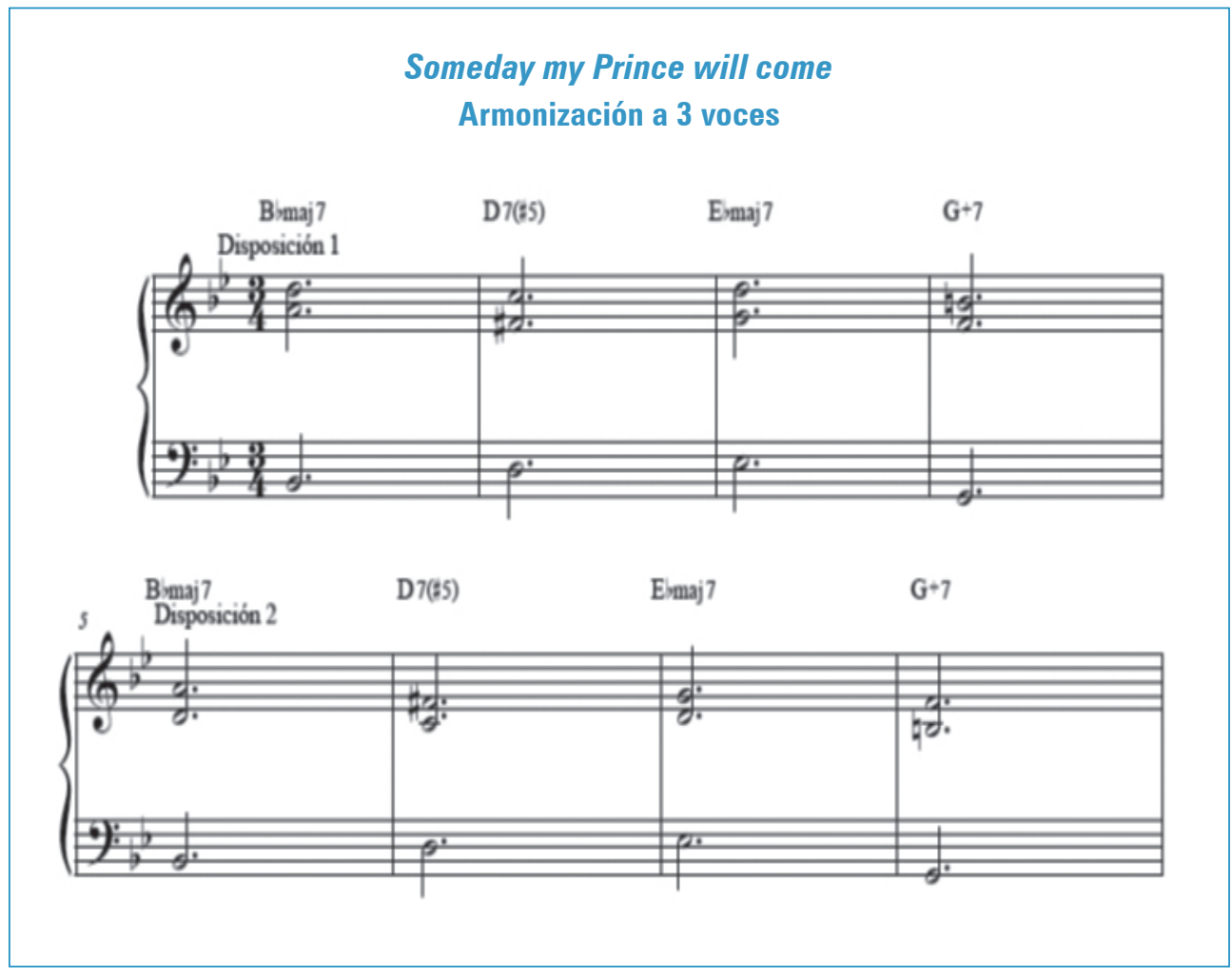

Fuente: (Benavides-Partimento, pg. 99, 2016)

El alumno debe tocar estrictamente la armonía a tres voces con las notas diacríticas de cada acorde. Deberá encontrar la mejor conducción de voces y trocarla en diferentes disposiciones en la mano derecha.

2. Armonización en tres voces con la melodía: El siguiente paso será realizar el lead-sheet con melodía, siempre por medio de la formación de una armonía en tres voces, en la que se expresen en todos los casos las notas diacríticas de los acordes. El principio es el mismo: de modo invariable se tendrá el bajo expresado en el cifrado en la mano izquierda y la séptima y la tercera en la mano derecha. Habrá ocasiones en que la melodía complete la armonía expresada en el cifrado. Se deben probar todas las combinaciones posibles de disposición en la mano derecha para buscar mejores alternativas y también para ser lo más flexible y adaptable posible. 
Figura 20. Armonización a tres voces con melodía

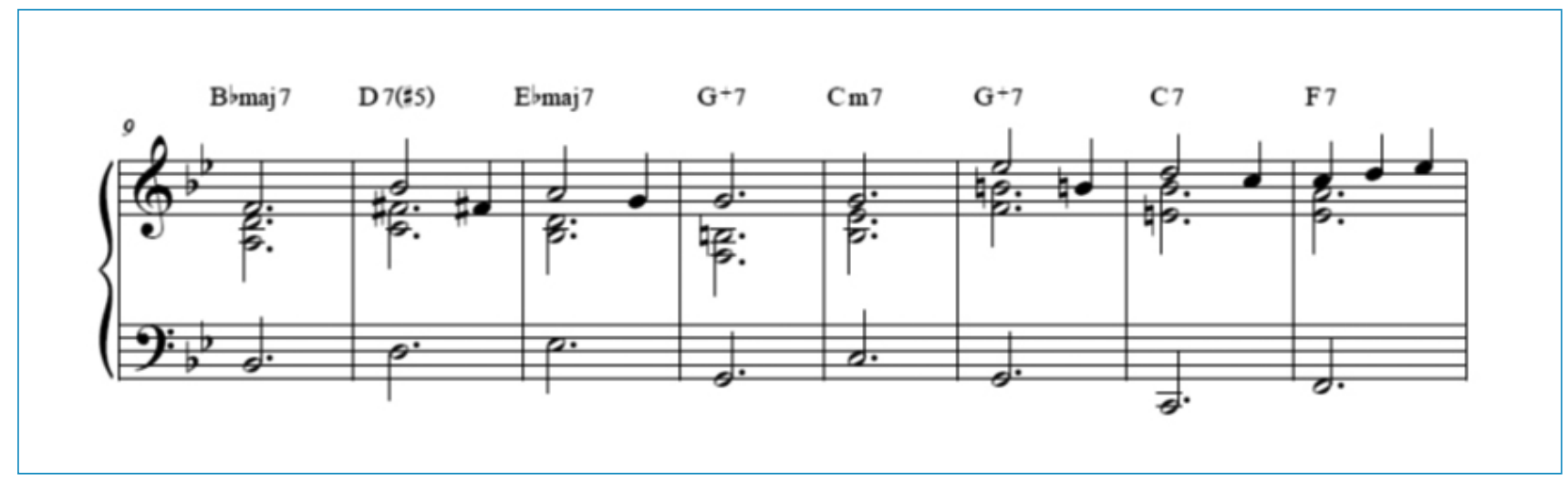

Fuente: (Benavides-Partimento, pg.99, 2016)

En ocasiones, la melodía puede ser un retardo de una de las notas del acorde, como en el tercer compás, donde la tercera está retardada.

3. Armonización en cuatro voces con rearmonizaciones y acordes de $9 \underline{a}$, $11^{\mathfrak{a}}$ y 13aㅡ : El paso siguiente es introducir la armonía en cuatro voces. Se recomienda empezar con piezas más modernas en las que sea absolutamente necesario introducir acordes de 9 ${ }^{a}, 11^{\underline{a}}$ y $13^{\underline{a}}$ como la balada blues Come Sunday, de Duke Ellington, en la que se presentan todas estas "innovaciones" en cuanto al lenguaje armónico. El maestro bien puede servirse de todo el repertorio del jazz moderno para introducir al alumno a este nuevo vocabulario.

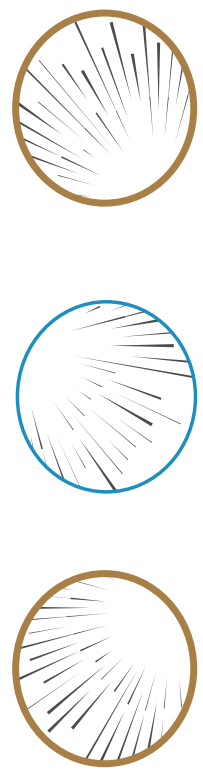


Figura 21. Come Sunday, standard de jazz

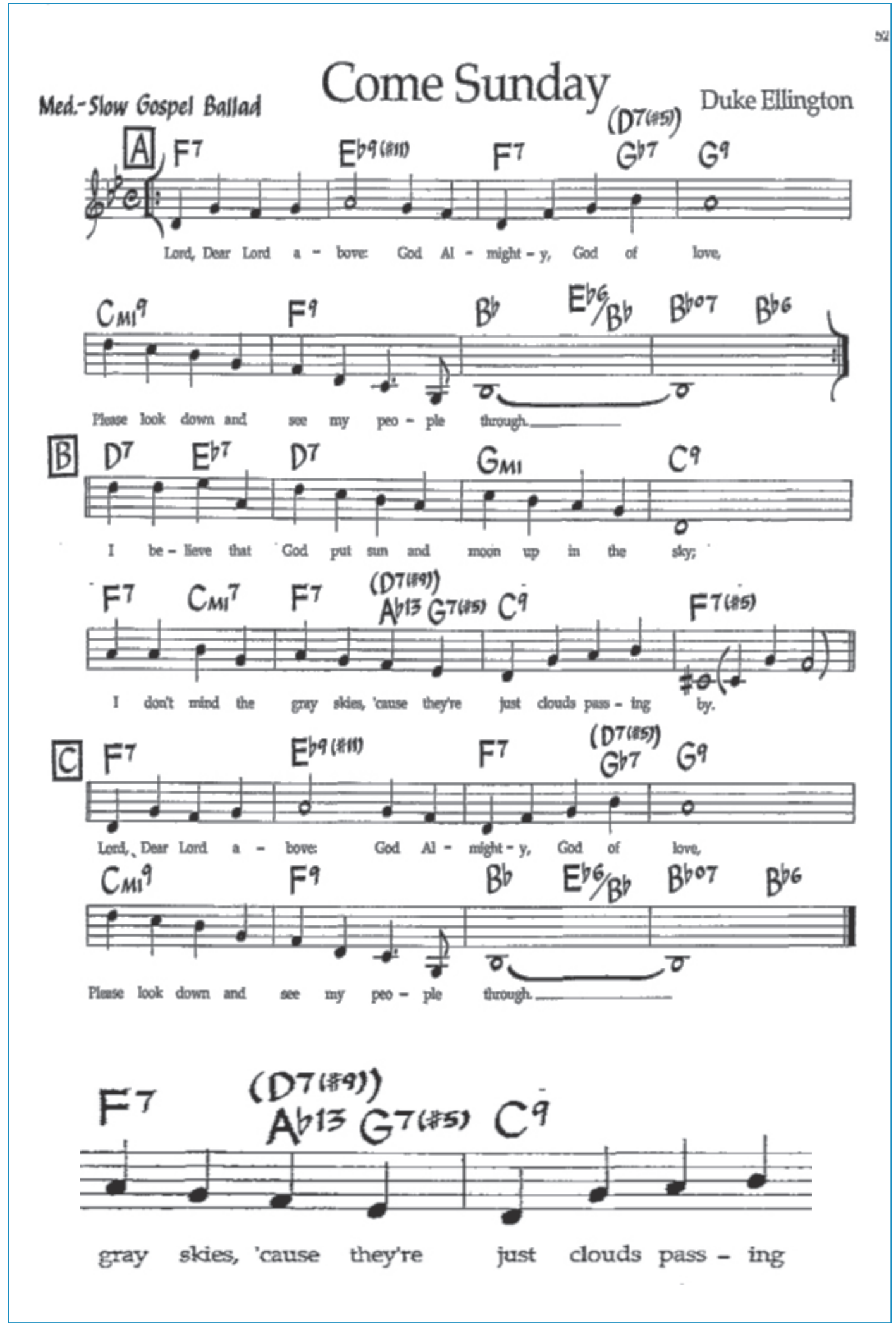

Fuente: (Sher Music Co., p. 52, 1988) 
Este pasaje de Come Sunday presenta un ejemplo de sustitución armónica al tritono. Aquí bien puede realizarse el patrón II-V-I ó VIb-V-I.

Figura 22. Come Sunday

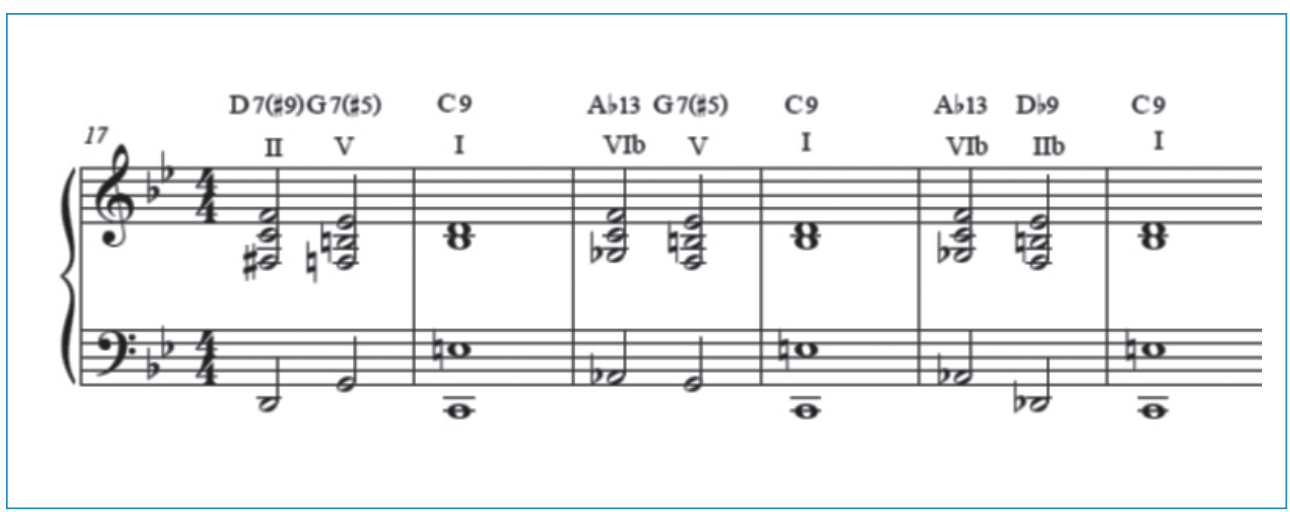

Fuente: (Benavides-Partimento, pg. 101, 2016)

Algunas sustituciones armónicas posibles del pasaje de Duke Ellington. La tercera opción muestra claramente el principio de sustitución al tritono de un patrón II-V-I.

Al inicio, puede seguirse el mismo principio de armonización en tres voces con melodía. Después se recomienda que para ir aprendiendo la armonización en cuatro voces se trabaje primero sin melodía, solo con los acordes, estudiando con un tempo regular, para afinar los reflejos. Esta armonía no presenta la dificultad del doblaje de voces ni de la de evitar el paralelismo, puesto que la presencia de tantas disonancias en el acorde quita de encima la dificultad de tener que doblar una voz, y el paralelismo, si existe, no molesta en este contexto.

Para proponer rearmonizaciones se puede empezar con la introducción de la práctica de las sustituciones de acordes al tritono. Se recomienda que se practique con patrones armónicos de II-V-I ${ }^{7}$ aislados para afinar los reflejos, con el fin de aplicarlos a la música misma después.

\section{Improvisación}

No entraré a analizar la improvisación en el teclado en jazz, puesto que no tengo mucha experiencia en este campo, dado que mi entrada a dicho género ha sido casi por completo intuitiva y únicamente desde mi punto de vista de instrumentista melódico.

7 Cuando estudiaba en Medellín, Colombia, tomé una electiva de jazz con Juan Diego “Juancho" Valencia, músico jazzista y compositor de gran renombre en mi país natal. Él decía que las formas básicas que resumen el jazz, y que hay que dominar para alcanzar la maestría, son: el blues de doce compases (y sus variantes), las progresiones II-V-I y la forma giant-steps, que toma el nombre del standard del mismo nombre, que es una forma sui géneris en el jazz. Desde luego, todo esto es un universo aparte. Es impresionante ver la enorme cantidad de semejanzas que hay en la manera de abordar la improvisación en los siglos XX y XXI en comparación con cómo se hacía en el siglo XVIII con el partimento y el bajo continuo. 
Por lo que alcanzo a observar, el método para improvisar es el mismo, tanto en el jazz como en la improvisación historicista. La práctica de fórmulas melódicas, el abordaje de pequeñas formas para luego enfrentarse a estructuras más grandes, las idas y venidas entre análisis y práctica para refinar el estilo, etc., son un claro ejemplo. Como es obvio, cada estilo está inscrito en un contexto cultural absolutamente diferente; además, cada género desarrolló elementos más que otros, lo que son ejemplos el caso del contrapunto en la tradición clásica europea, en contraposición a la inmensa riqueza del lenguaje rítmico del jazz, pero podría decirse que los principios de trabajo son casi los mismos.

\section{Puente entre jazz e impresionismo: el caso de Beau soir de Debussy}

Si el objetivo es entender los rudimentos del lenguaje impresionista a través de la práctica del lead-sheet o el real book del jazz, una vez que el alumno conoce las reglas de funcionamiento, se enfrentará al desafío de reinvención de una pieza de repertorio, sea de Debussy, de Ravel u otro. El maestro hará síntesis reducida a un lead-sheet semejante a los de jazz de una pieza de uno de estos maestros. Se sugiere tomar las piezas de juventud, puesto que no presentan tanta complejidad como las obras maduras.

He aquí un buen ejemplo para empezar, una de las canciones de juventud del compositor Claude Debussy.

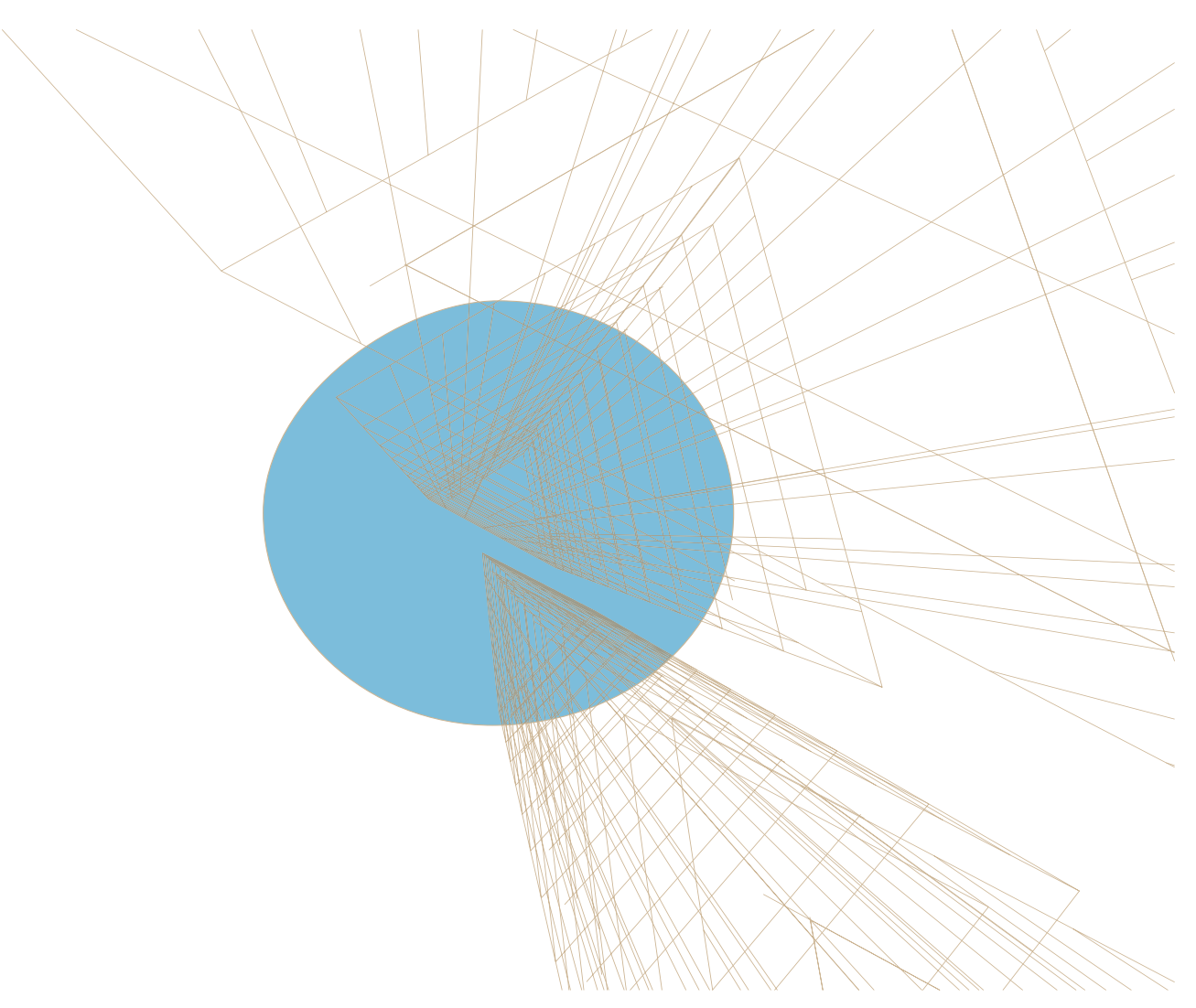


Figura 23. Beau soir en su versión original

EVENING FAIR

(BEAU SOIRI

PAUL BOURGET (AsMe- ,

Icumpord is iss

Thenslated by Froderied A. Nartens
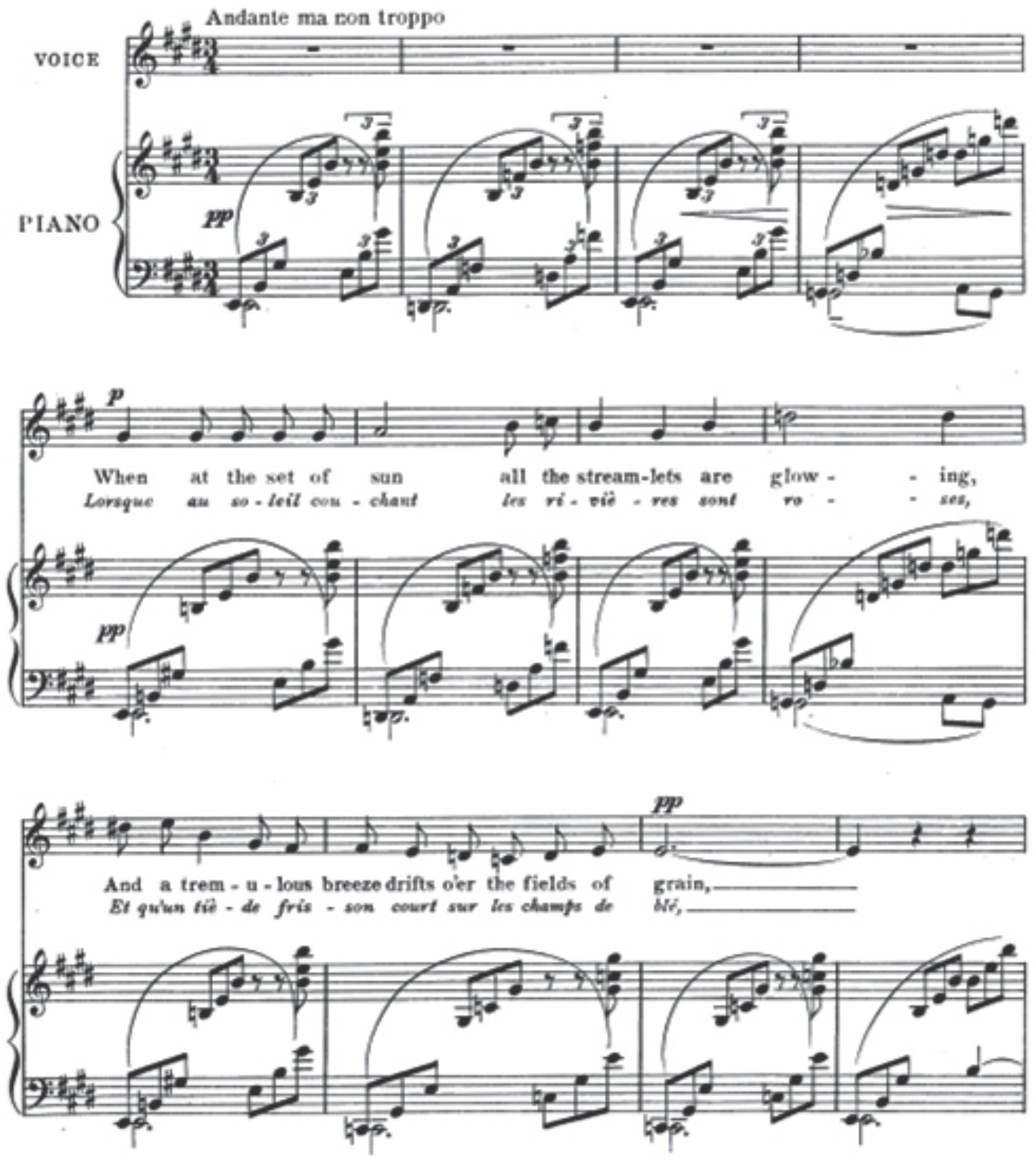

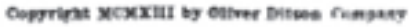


Figura 24. Beau soir reducida a un lead-sheet por David Chappuis

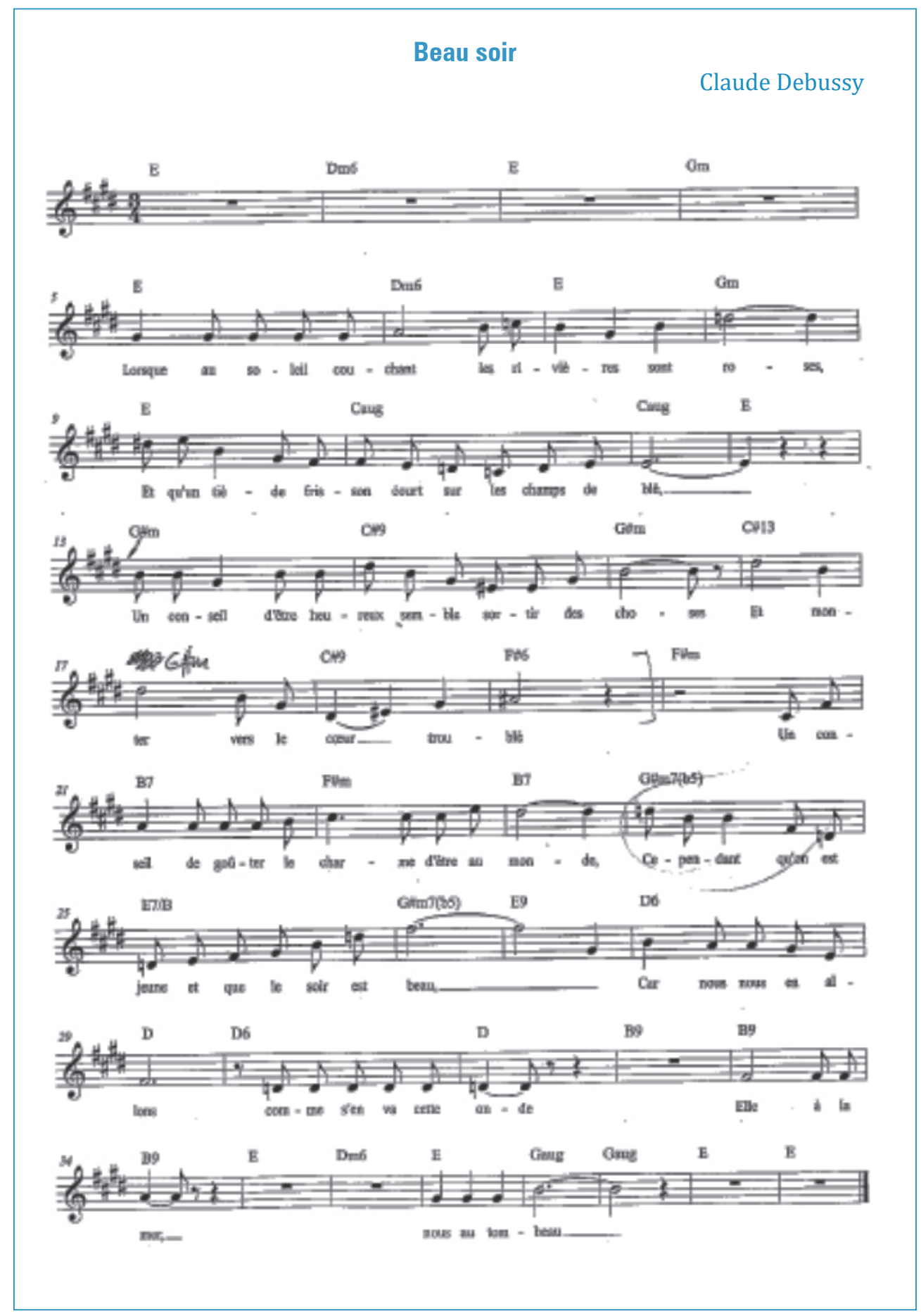

Fuente: Chappuis (2014-2015)
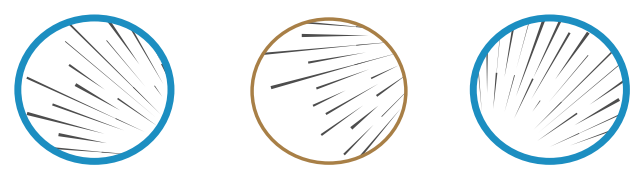


\section{Una canción popular armonizada en estilo impresionista}

Otro reto interesante es probar la armonización impresionista sobre una canción popular que presente una estructura armónica muy sencilla. Así, el alumno podrá experimentar con sustituciones de acordes, notas agregadas, disonancias y demás innovaciones armónicas. Después podrá probar a hacer variaciones o, incluso, una fantasía sobre el tema. Aquí las posibilidades que se abren son infinitas.

Se recomienda trabajar sobre repertorio de origen popular folklórico, siempre con armonías muy simples.

Con posterioridad el alumno podrá improvisar formas libres, al seguir el ejemplo de los grandes maestros impresionistas. De nuevo, el trabajo de ida y venida entre análisis de repertorio, escritura y práctica es esencial para ir fortaleciendo el estilo.

\section{Conclusiones}

Para la implementación de la improvisación se puede aplicar un principio, ya implementado por el aprendizaje de las lenguas, en el que se aprende primero a hablar antes de aprender a leer y escribir. La enseñanza de esta práctica va de la mano con el ejercicio práctico, a partir de premisas y ejercicios concretos. El fenómeno de separación de teoría y práctica es algo típicamente occidental.

Si se establece un curso de formación musical en el que interpretación, composición, improvisación y análisis van juntos, como es el caso de la improvisación, el progreso en la comprensión del lenguaje musical se acelera en forma exponencial. Se propicia, también, un gratificante espacio de aprendizaje en el que se estimulan de manera constante la proactividad y la creatividad.

La tradición de la música clásica, en la que se incluyen tanto su pedagogía y sus ritos de socialización como su práctica musical, debe reinventarse a sí misma si quiere sobrevivir a los tiempos modernos de cambios tan abruptos y acelerados. El redescubrimiento de las prácticas de improvisación olvidadas por el paso del tiempo, su actualización y puesta en escena en nuestros recitales habituales, destruir preconceptos de la música que no corresponden a su realidad histórica y la capacidad de forjar puentes con tradiciones musicales hermanas, pueden ser elementos esenciales para la reivindicación social de la música académica.

Instaurar la práctica de la improvisación como una experiencia integral y central de los currículos que forman al músico académico actual requiere cambiar la estructura social sobre la que está construida la tradición, que reposa netamente en el ejercicio de lectura, lo cual limita la posibilidad de práctica musical y hace más difícil el ejercicio de la profesión, en una sociedad en la que cada vez hay menos voluntad política para mantener vivas a las orquestas sinfónicas. Pero, de manera eventual, los conservatorios habrán de considerarlo si quieren sobrevivir al cambio y oxigenar la tradición. Algo que podría comenzar a implementarse es la instauración de las clases de improvisación idiomática (diferente a la libre) como asignatura obligatoria en la formación de los instrumentistas, lo que estaría acompañado de piezas improvisadas como parte los recitales, con el fin de instaurar una práctica musical de referencia que justifique la pertinencia de la improvisación. Esta destreza podrá darles mayor facilidad a los instrumentistas de abordar estilos modernos que reposan en la oralidad, lo que les permitirá ampliar su campo de acción y los llevará a ser artistas más creativos. 


\section{Bibliografía}

Chappuis, D. (2014-2015). Clase de Armonía Práctica de Tercer Año. Maestría de Teoría Musical. Ginebra, Suiza.

Festival de Musique Improvisée de Lausanne. (s.f.). fmil.org. Recuperado el 4 de Abril de 2016, de http://www.fmil.org/festival.php?fmil=festival

Lutz, R. (2010). The Playing of Partimento: COMPREHENSIVE TRAINING FOR THE COMPOSING AND IMPROVISING INTERPRETER. En R. G. Thomas Christensen, Partimento and Continuo Playing in Theory and in Practice. Leuven University Press.

Marco, B. d. (2014). Conflicto entre Teoría y Práctica en la realidad del Músico Instrumentista". Ginebra: Haute École de Musique de Genève.

Montagnier, J.-P. C. (2009). Principes de Composition de Nicolas Bernier. Langres: Éditions Dominique Guéniot.

Paisiello, G. (s.f.). imslp.org. Recuperado el 19 de Septiembre de 2016, de http:// imslp.org/wiki/Regole_musicali_per_i_principianti_di_cembalo_(Fenaroli,_Fedele)

Sanguinetti, G. (2007). The Realization of Partimento. Journal of Music Theory, 51-83.

Sanguinetti, G. (2012). The Art of Partimento. New York: Oxford University Press.

\section{Imágenes referenciadas}

Chappuis, D. (2014-2015). Clase de Armonía Práctica de Tercer Año. Maestría de Teoría Musical. Ginebra, Suiza.

Montagnier, J.-P. C. (2009). Principes de Composition de Nicolas Bernier. Langres: Éditions Dominique Guéniot.

Paisiello, G. (s.f.). imslp.org. Recuperado el 19 de Septiembre de 2016, de http:// imslp.org/wiki/Regole_musicali_per_i_principianti_di_cembalo_(Fenaroli,_Fedele) 